\author{
UNIVERSIDADE DE SÃO PAULO \\ ESCOLA DE ENGENHARIA DE SÃO CARLOS \\ DEPARTAMENTO DE ENGENHARIA ELÉTRICA
}

\title{
ANÁLISE DE OBSERVABILIDADE PARA O ESTIMADOR DE ESTADOS E PARÂMETROS
}

\section{FERNANDO SILVA PEREIRA}

Dissertação apresentada à Escola de Engenharia de São Carlos da Universidade de São Paulo, como parte dos requisitos para obtenção do Título de Mestre em Engenharia Elétrica.

ORIENTADOR: Prof. Dr. Newton G. Bretas

São Carlos

2005 


\section{SUMÁRIO}

AGRADECIMENTOS

III

RESUMO

VI

ABSTRACT

VII

\section{CAPÍTULO 1}

1. INTRODUÇÃO

1

1.1 Organização e Objetivos

\section{CAPÍTULO 2}

2. REVISÃO BIBLIOGRÁFICA

2.1 Introdução

2.2 Análise de Observabilidade

2.3 Estimação de Parâmetro

2.3.1 Métodos para Estimação e Identificação de Erros de Parâmetros

\section{CAPÍTULO 3}

3. ESTIMAÇÃO DE ESTADOS EM SISTEMAS ELÈTRICOS DE POTÊNCIA

3.1 Estimador de Estados Linear por Mínimos Quadrados

3.2 Detecção e identificação de medidas com erros grosseiros

3.3 Identificação de medidas com erros grosseiros

3.4 Estimador de Estados e Parâmetros baseados nas Equações Normais 


\section{CAPÍTULO 4}

4. ANÁLISE DE OBSERVABILIDADE 19

$\begin{array}{ll}4.1 \text { Desacoplamento do modelo } & 19\end{array}$

4.2 Análise de observabilidade baseada na fatoração triangular da matriz Ganho e em conceitos de caminhos de fatoração 22

4.2.1 Algoritmo para Análise de Observabilidade 24

4.2.2 Algoritmo para Identificação de Ilhas Observáveis 24

4.3 Exemplo $\quad 25$

\section{CAPÍTULO 5}

5. MÉTODO PARA ANÁLISE DE OBSERVABILIDADE PARA O MODELO AUMENTADO 33

5.1 Introdução 33

5.2 Análise de observabilidade para o modelo aumentado 33

5.2.1 Estrutura da matriz Ganho Aumentada 34

$\begin{array}{ll}5.3 \text { Algoritmo } & 38\end{array}$

$\begin{array}{ll}5.4 \text { Exemplo } & 39\end{array}$

\section{CAPÍTULO 6}

6. TESTES E ANÁLISE DOS RESULTADOS 48

6.1 Testes com o sistema de 6 barras do IEEE 48

6.2 Testes com o sistema de 14 barras do IEEE 55

6.3 Testes com o sistema de 30 barras do IEEE 63

$\begin{array}{ll}6.4 \text { Análise dos resultados } & 67\end{array}$

\section{CAPÍTULO 7}

7. CONCLUSÕES

$\begin{array}{lr}\text { BIBLIOGRAFIA } & 69\end{array}$ 


\section{Resumo}

Neste trabalho propõe-se um método de análise de observabilidade para estimação de estados e parâmetros em sistemas elétricos de potência, baseado nas Equações Normais. O método fundamenta-se na fatoração triangular da matriz ganho aumentada e nos conceitos de caminhos de fatoração. O mesmo utiliza rotinas já existentes no processo de estimação, sendo simples, de fácil implementação, rápida execução e não exige a solução de equações algébricas. Para comprovar a sua eficiência vários testes foram realizados, utilizando os sistemas de 6, 14 e 30 barras do IEEE, tendo sido satisfatórios os resultados obtidos.

Palavras-chave: Sistemas de Potência, Estimação de Estados e Parâmetros, Análise de Observabilidade. 


\section{Abstract}

In this work we propose a method of observability analysis for states and parameters estimation in electric power systems, based on the Normal Equations. The method is based on triangular factoration of the augmented gain matrix and on the concepts of factoration paths. It uses routines that there exist in the estimation process. These routines are simple, of easy implementation, fast execution and it doesn't demand the solution of algebraic equations. To prove your efficiency several tests were accomplished, using the 6, 14 and 30bus IEEE test systems. The obtained results were satisfactory.

Key - words: Power systems, State estimation, parameter estimation, observability analysis. 


\section{Capítulo 1}

\section{Introdução}

Para uma operação adequada, em tempo real, dos sistemas elétricos de potência, é necessário saber os estados ${ }^{1}$ do sistema. A ferramenta utilizada nos modernos centros de operação (COs), para a obtenção destes estados, é o estimador de estados.

A estimação de estados consiste na obtenção, em tempo real, dos estados de um sistema elétrico de potência, através do processamento de um conjunto redundante de medidas com ruído (medidas analógicas ${ }^{2}$ e lógicas ${ }^{3}$ ) e de informações estáticas disponíveis no banco de dados dos centros de operação das companhias de energia elétrica (os parâmetros ${ }^{4}$ do sistema).

Tradicionalmente são quatro as etapas envolvidas no processo de estimação de estados, sendo que o fracasso de uma delas inviabiliza todo o processo:

1ª Etapa: Obtenção da topologia do sistema (modelo barra/linha)

A partir das medidas lógicas, bem como de informações quanto ao tipo e a localização dos medidores instalados no sistema, o configurador de sistema permite determinar a topologia e a correspondente configuração de medidores

\footnotetext{
${ }^{1}$ Tensões complexas nas barras do sistema.

${ }^{2}$ Medidas de fluxo de potência ativa e reativa nas linhas, injeção de potência ativa e reativa e algumas magnitudes de tensão nas barras.

${ }^{3}$ Consiste em estados de chaves e disjuntores.

${ }^{4}$ Impedância de linhas de transmissão e posição de taps de transformadores.
} 
no modelo barra/linha. Importa salientar que as informações processadas pelo configurador são modeladas ao nível de seção de barra (representação física dos elementos do sistema).

2a Etapa: Análise e restauração da observabilidade do sistema

Através do modelo barra/linha obtido pelo configurador de sistema, verifica-se se é possível, através das medidas analógicas e virtuais disponíveis, estimar o estado de todas as barras do sistema.

Em caso afirmativo, o sistema é dito observável como um todo, com relação ao conjunto de medidas disponível.

No caso de as medidas disponíveis não serem suficientes para determinar todos os estados do sistema, importa determinar as partes observáveis do mesmo, isto é, as ilhas observáveis.

Outra alternativa para esta falta de medidas pode ser a adição de pseudomedidas ${ }^{5}$ ao conjunto de medidas, através das quais o sistema se torna observável como um todo.

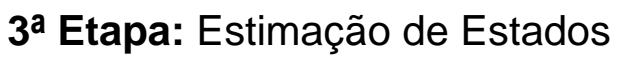

Considerando a topologia do sistema, obtida pelo configurador de sistema, e através de seus parâmetros armazenados no banco de dados, bem como do conjunto disponível de medidas analógicas e virtuais ${ }^{6}$, o estimador de estados (EE) permite determinar o estado de todas as barras do sistema.

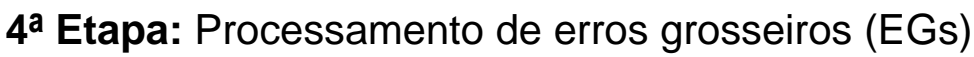

As medidas analógicas fornecidas ao EE estão sujeitas aos EGs, que levam o processo de estimação a estados não verdadeiros, ou, até mesmo, a não convergência ${ }^{7}$. Devido a essa fragilidade do conjunto de medidas, o EE deve ser robusto o suficiente para detectar e identificar a ocorrência de medidas com EGs.

\footnotetext{
${ }^{5}$ Pseudomedidas são dados de previsão de carga, previsão de geração, dados históricos, etc, que fazem parte do banco de dados dos COs.

${ }^{6}$ Medidas virtuais são medidas de injeção zero em barras passivas do sistema.

${ }^{7}$ Em razão das não linearidades envolvidas na formulação do EE não linear, a sua solução requer o uso de métodos iterativos, que dependendo da magnitude do erro grosseiro, pode não convergir.
} 
Em seguida, as medidas identificadas como portadoras de EGs são eliminadas do conjunto de medidas e os estados são estimados novamente.

Além dos erros grosseiros, o estimador de estados está sujeito ainda a erros topológicos $^{8}$ e erros de parâmetros ${ }^{9}$. Se esses erros não forem detectados pelo configurador do sistema ( $1^{\mathrm{a}}$ etapa), ou nas etapas que precedem a estimação de estados, eles podem causar um aumento nos resíduos das medidas analógicas, localizadas nas vizinhanças dos elementos/parâmetros erroneamente configurados do sistema.

Assim, na 4ª Etapa, as medidas analógicas, com resíduos elevados, são identificadas como portadoras de erros grosseiros. Nessa situação, dar-se-á início a um processo de eliminação dessas medidas, e, eventualmente, o processo poderá reduzir a zero o nível de redundância local, ou seja, teremos apenas uma medida dando informação daquele estado. Logo, não será mais detectado erro grosseiro em medida analógica, pois o resíduo daquela medida será zero, mas o erro topológico e/ou de parâmetro permanece. Conseqüentemente, os estados estimados não representarão corretamente a situação atual do sistema.

É drástico o efeito de um erro de parâmetro, para o processo de estimação de estados, normalmente intolerável, e os erros de parâmetros são menos evidentes do que os erros grosseiros e topológicos.

O número de trabalhos relacionados a erros de parâmetros é modesto, se comparado com aqueles dedicados a erros grosseiros e topológicos [ZARCO; EXPÓSITO (2000)].

Dentre os métodos desenvolvidos para o tratamento de erros de parâmetros, destacam-se os que se baseiam nas equações normais e aumentam o vetor de estados para considerar os parâmetros a serem estimados.

A grande limitação desses métodos está relacionada com a observabilidade, isto é, raramente o número de medidas disponível é suficiente para estimar todos os estados "aumentados"10, uma vez que o vetor de estados

\footnotetext{
${ }^{8}$ Erros nas medidas lógicas, devido a informações incorretas quanto ao estado de chaves e/ou disjuntores.

${ }^{9}$ Erros devido a informações erradas de algum parâmetro.

${ }^{10}$ Vetor de estados, constituído pelas tensões complexas e pelos parâmetros a serem estimados.
} 
aumenta, mas o conjunto de medidas permanece o mesmo. Logo, são necessários métodos para verificar quais estados aumentados podem ser estimados $^{11}$.

\subsection{Objetivos e Organização}

A proposta deste trabalho é desenvolver um método para análise de observabilidade, para o estimador de estados e parâmetros baseado nas equações normais. A partir das medidas disponíveis, o método proposto deve determinar as porções observáveis do sistema, isto é, os estados e parâmetros observáveis. Para isso utilizaremos como base o método para análise e restauração de observabilidade, desenvolvido por BRETAS (1996) ${ }^{12}$.

Este trabalho é organizado como segue: um pequeno histórico das pesquisas em estimação de estados e análise de observabilidade é apresentado no Capítulo 2. No capítulo 3 apresenta-se um resumo contendo a formulação básica do estimador de estados por mínimos quadrados ponderados, bem como a formulação do estimador de estados e parâmetros. No Capítulo 4 descreve-se, em linhas gerais, o método para análise de observabilidade desenvolvido por BRETAS (1996). No Capítulo 5 encontra-se o método proposto, e no Capítulo 6 são apresentados alguns exemplos da sua aplicação. As conclusões acham-se no Capítulo 7.

\footnotetext{
${ }^{11}$ Identificar as ilhas observáveis.

${ }^{12}$ O método desenvolvido em BRETAS (1996) é para o estimador de estados tradicional, isto é, sem a inclusão dos parâmetros como estados a serem estimados.
} 


\section{Capítulo 2}

\section{Revisão Bibliográfica}

Neste capítulo apresentam-se alguns métodos para estimação de parâmetros e análise de observabilidade, para sistemas de potência encontrados na literatura. Esta revisão bibliográfica tem o objetivo de apresentar a base teórica, para o desenvolvimento deste trabalho.

\subsection{Introdução}

Professor Schweppe foi o primeiro a propor o desenvolvimento do estimador de estados, para monitoramento de sistemas de potência. Em 1970, Schweppe e colaboradores apresentaram uma série de três artigos, descrevendo a natureza geral do problema, o modelamento matemático, as técnicas iterativas para o cálculo da estimação e conceitos relacionados com a detecção e à identificação de medidas com erros grosseiros [SCHWEPPE; WILDES (1970), SCHWEPPE; DOUGLAS (1970), SCHWEPPE (1970)].

O estimador de estados pode ser considerado uma generalização do problema clássico de fluxo de carga. A vantagem do estimador de estados sobre o fluxo de carga usual é a capacidade de manipular dados redundantes e sujeitos a erros. Desde então, o assunto tem chamado atenção de muitos 
pesquisadores que, visando a métodos mais lógicos e aplicáveis em tempo real, realizaram pesquisas diversas em [COUTTO FILHO et al. (1990)]:

- Estimação de estados;

- Análise de observabilidade;

- Detecção e identificação de erros grosseiros;

- Planejamento de sistemas de medidas confiáveis, etc.

\subsection{Análise de Observabilidade}

A verificação da observabilidade do sistema é uma condição necessária para o sucesso da estimação de estados.

De uma forma geral, os métodos para análise e restauração da observabilidade podem ser divididos em dois grupos: os métodos topológicos e os métodos numéricos.

Os métodos topológicos caracterizam-se pela criação de rotinas específicas, que não exigem cálculos, mas são de natureza combinatorial e complexas. Os métodos numéricos são mais simples, sendo fácil sua implementação, pois utilizam rotinas já disponíveis nos programas de estimação de estados. Contudo, estes estão sujeitos a erros numéricos.

FETZER; ANDERSON (1975) desenvolveram um método para análise de observabilidade, que determinava a melhor medida a ser adicionada ao conjunto de medidas, através da análise dos autovetores, associados aos autovalores da matriz Ganho do estimador de estados. Mas o requerimento computacional inviabilizava a sua aplicação, em termos de implantação em tempo real.

Através do conceito de redes topologicamente observáveis, KRUMPHOLZ; DAVIS (1980) criaram um algoritmo para a análise de observabilidade, utilizando conceitos da teoria de grafos. Neste trabalho, os autores definem os conceitos de observabilidade algébrica, numérica e topológica.

QUINTANA et al. (1982), utilizando também o conceito de observabilidade topológica, o qual requer a construção de uma árvore 
representativa de posto completo $^{1}$, para que o sistema seja observável, apresentam um método utilizando um algoritmo "matroid intersection", com testes em sistema reais.

Buscando menos complexidade computacional, MONTICELLI; WU (1985ab) desenvolveram um método simples e de fácil implementação, utilizando sub-rotinas já existentes em programas de estimação de estados, para testar a observabilidade da rede e identificar ilhas observáveis, caso o sistema seja não observável como um todo, através da fatoração triangular da matriz ganho.

SLUTSKER; SCUDDER (1987) apresentam um método baseado na redução simbólica da matriz Jacobiana. O método se caracteriza por ser extremamente simples e rápido. Neste método, os autores não levam em conta o valor real dos elementos não nulos da matriz Jacobiana e sim a posição desses elementos. Três anos depois, CHEN (1990) apresentou uma versão modificada desse método, considerando valores inteiros para os elementos não nulos da matriz Jacobiana.

CONTAXIS; KORRES (1988) propuseram um algoritmo que utiliza em conjunto as análises de observabilidade topológica e numérica. O tamanho da rede é reduzido através de processos topológicos e então a análise e restauração da observabilidade são realizadas, através de processos numéricos. Uma vez que a rede é reduzida, a quantidade de cálculos necessários também é reduzida.

Tendo em vista a otimização combinatorial, um algoritmo topológico e eficaz em relação à rapidez da sua execução é apresentado por NUCERA; GILLES (1991), com testes em sistemas reais. Os autores ainda fazem comparações com algoritmos de observabilidade numérica, para demonstrar a eficácia do algoritmo. Ainda em 1991, MORI; TSUZUKI (1991) apresentam outro método, baseado na árvore representativa mínima e na teoria de grafos.

Em MONTICELLI et al. (1992), problemas que podem aparecer nas análises de observabilidade, realizadas por métodos em que se consideram apenas informações topológicas, foram apresentados. Para tratar dessa

\footnotetext{
${ }^{1}$ Árvore representativa de posto completo é uma árvore que, além de relacionar todas as barras do sistema, possui uma medida distinta associada a cada um de seus ramos.
} 
limitação, os autores sugerem um método numérico de análise de observabilidade, baseado na fatoração triangular da matriz Ganho.

Algum tempo depois, BRETAS (1996) desenvolveu um método baseado em conceitos de caminhos de fatoração e na fatoração triangular da matriz Ganho. É um método simples, que não exige a solução de equações algébricas e de fácil implementação, uma vez que usa sub-rotinas já existentes em programas destinados à estimação de estados.

\subsection{Estimação de Parâmetros}

$\mathrm{Na}$ próxima seção, vamos citar e comparar alguns dos métodos desenvolvidos para estimação de parâmetros e identificação de erros nos mesmos. Entretanto, uma comparação mais precisa desses métodos é difícil de ser realizada, pelo fato de que cada um dos artigos publicados se refere a diferentes sistemas e diferentes dados de entrada. Além disto, muitas contribuições relevantes omitem a informação sobre a precisão das medidas utilizadas nos experimentos.

\subsubsection{Métodos para estimação e identificação de erros de parâmetros}

De uma forma geral, os métodos desenvolvidos para o tratamento de erros de parâmetros podem ser divididos em dois grupos:

Grupo 1: Métodos baseados na análise da sensibilidade dos resíduos²;

Grupo 2: Métodos que aumentam o vetor de estados.

Os métodos dos dois grupos dependem de uma estimação de estados convencional, para a determinação dos ramos suspeitos ${ }^{3}$ de estarem com erros de parâmetros.

\section{Grupo 1: Métodos baseados na análise da sensibilidade dos resíduos}

\footnotetext{
${ }^{2}$ Resíduos de estimação é a diferença entre o valor medido e o valor estimado das medidas.

${ }^{3}$ Ramos incidentes às medidas com resíduos elevados.
} 
Os métodos deste grupo utilizam o vetor de estados convencional e baseiam-se na análise da sensibilidade dos resíduos das medidas incidentes aos ramos suspeitos. Através dessa análise identificam os parâmetros suspeitos de estarem com erros em seus valores.

Em FLETCHER; STADLIN (1983), apresentou-se um método para estimação da posição de taps de transformadores, que se baseia na forte relação entre o fluxo de potência reativa, através do transformador, e a posição do tap do mesmo. Os ramos com transformadores suspeitos de conterem erros na posição do tap são identificados através da análise dos resíduos. A diferença entre os fluxos de potência reativa medidos e os calculados, através do transformador, é utilizada para verificar se a posição do tap é correta ou não. Os autores definem a posição inicial do tap como sendo metade da escala de variação do transformador (em SMITH (1985) o valor inicial do tap é definido como sendo 1 p.u.).

LIU et al. (1992) propuseram um novo tratamento do vetor de resíduo, que possibilita a estimação do erro de parâmetro. Uma vez obtidos os erros de parâmetros, é possível corrigir os parâmetros errados do sistema. As limitações desse método são: número grande de iterações, pois o método faz duas estimações independentes ${ }^{4}$; as matrizes utilizadas no processo de estimação dos erros de parâmetros são geralmente singulares, o que acarreta problemas de observabilidade; e os autores não consideram erros grosseiros nas medidas.

A grande limitação dos métodos, baseados na análise da sensibilidade dos resíduos, é conseguir distinguir entre o resíduo causado por um erro grosseiro daquele causado por um erro de parâmetro. Em muitas pesquisas realizam-se diversos testes, considerando que os sistemas tenham apenas erros de parâmetros, desconsiderando a possibilidade da ocorrência de erros também em medidas analógicas, tornando o modelo bastante simplificado.

\footnotetext{
${ }^{4}$ A primeira para estimar os resíduos e a segunda para estimar os erros de parâmetros.
} 


\section{Grupo 2: Métodos que aumentam o vetor de estados}

Os métodos deste grupo aumentam o vetor de estados, para incluirem os parâmetros suspeitos, como se eles fossem variáveis independentes. Desta maneira, os parâmetros são estimados juntamente com as tensões complexas das barras do sistema de potência.

Uma das alternativas para trabalhar com esse modelo aumentado é através das equações normais, que é exatamente a mesma formulação do estimador de estados convencional, porém com o vetor de estados aumentado.

O método proposto por ALLAN; LAUGHTON (1974) foi um dos primeiros métodos de estimação de estados e parâmetros a desenvolver-se dessa maneira. Além de estimar estados e parâmetros, através da diferença entre os valores dos parâmetros fornecidos pelo banco de dados e os seus valores estimados, esse método permite identificar se os ramos do sistema estão fora de operação ou não.

Com a inclusão de estados relacionados à topologia e aos parâmetros do sistema, no processo de estimação de estados, o método proposto em ALSAÇ et al. (1998) permite uma melhor discriminação entre erros grosseiros, topológicos e de parâmetros. Primeiramente, o estimador de estados convencional é processado e a análise de resíduos é efetuada sem o aumento do vetor de estados. As porções da rede, cujas medidas contém resíduos acima do esperado, são selecionadas e a estimação é feita localmente, incluindo agora as chaves e os parâmetros do sistema, no vetor de estados. A análise dos resíduos vai indicar onde estão localizados os erros.

A limitação dos métodos que usam equações normais está relacionada à observabilidade, isto é, raramente o número de medidas disponível é suficiente para estimar todos os estados "aumentados", uma vez que o vetor de estados aumenta, mas o conjunto de medidas continua o mesmo.

Para solucionar esse problema, foram propostos métodos baseados na teoria do filtro de Kalman.

Para evitar o problema de observabilidade, estes métodos aumentam o vetor de medidas com pseudomedidas, referentes aos estados e parâmetros estimados no instante anterior. 
Em DEBS (1974), mostrou-se a possibilidade de se estimarem os estados e parâmetros, através de um algoritmo recursivo baseado no filtro de Kalman. Os parâmetros são modelados como sendo constantes e as tensões complexas das barras são atualizadas segundo o processo de Markov. Experiências computacionais indicaram que tal formulação tem problemas de convergência, quando aplicada a sistemas grandes e/ou com muitos parâmetros incorretos. Além disso, esta formulação trata as medidas como sendo exatas e os parâmetros como constantes. Isto limita a flexibilidade do algoritmo, visto que alguns parâmetros, em razão das perdas por efeito corona, são variantes no tempo.

Diferindo do anterior, os parâmetros não são considerados constantes em SLUTSKER; CLEMENTS (1996), pois, assim como as tensões complexas das barras do sistema, eles também são atualizados, segundo o processo de Markov. Desse modo, permite a estimação de parâmetros variantes no tempo.

Em ZARCO; EXPÓSITO (2000), chega-se à conclusão de que para tratar parâmetros que variam no tempo, os métodos que utilizam o filtro de Kalman são os mais apropriados. Por outro lado, para os parâmetros que permanecem constantes, por um longo período de tempo, são mais apropriados os métodos que utilizam as equações normais.

A grande limitação dos métodos que se baseiam na teoria do filtro de Kalman está na determinação da matriz transição de estados. Muitos autores consideram essa matriz como sendo uma matriz identidade, isto é, consideram que os estados e parâmetros não sofrem mudanças no tempo. 


\section{Capítulo 3}

\section{Estimação de Estados em Sistemas Elétricos de Potência}

O problema de estimação de estados consiste em determinar uma forma de atingir-se a melhor estimativa dos estados desconhecidos. Para isto, dos muitos critérios estatísticos existentes, o mais utilizado, para estimação de estados em sistemas elétricos de potência, é o dos mínimos quadrados ponderados (W.L.S ${ }^{1}$ ).

O estimador de estados pode ser dinâmico ou estático. A grande limitação do estimador dinâmico está na determinação da matriz transição de estados. Na maioria dos artigos, essa matriz é considerada como sendo uma matriz identidade, assumindo que o sistema seja quase estático.

No estimador estático, supõe-se que o sistema esteja em condições de regime permanente, ou seja, não se considera a variação entre as grandezas envolvidas e o variável tempo. Por isso, a rede é representada por um conjunto de equações algébricas.

\footnotetext{
${ }^{1}$ Do inglês W.L.S. - Weighted Least Square.
} 


\subsection{Estimador de Estados não Linear por Mínimos Quadrados Ponderados}

Considere um sistema de potência com "nb" barras, no qual se realizam "m" medidas. O relacionamento entre essas medidas e os erros de medição é dado pelo seguinte modelo [SCHWEPPE, 1970]:

$$
\underline{z}=h\left(\underline{x}_{v}\right)+\underline{w}
$$

Onde: $\underline{z} \quad$ : vetor de medidas $(\mathrm{m} \times 1)$;

$\underline{h}($.$) : vetor de funções não lineares, que relaciona as medidas com$ os estados a serem estimados $(m \times 1)$;

$\underline{x}_{v}:$ vetor dos estados verdadeiros(nx1);

$\underline{w}$ : vetor dos erros nas medidas $(\mathrm{m} \times 1)$;

$\mathrm{n}$ : número de variáveis de estado.

A teoria de estimação por mínimos quadrados ponderados pode ser formulada sem que se façam hipóteses estatísticas sobre $\underline{x}_{v}$ ou $\underline{w}$. Pode-se dizer simplesmente que uma estimativa de " $\underline{x}_{v}$ " pode ser obtida determinandose o valor de $\underline{x}$, que minimize um determinado índice $J(\underline{x})$ dado por:

$$
\begin{aligned}
& J(\underline{x})=\underline{w}^{t} W^{-1} \underline{w} \\
& \text { ou } \\
& J(\underline{x})=[\underline{z}-h(\underline{x})]^{t} W^{-1}[\underline{z}-h(\underline{x})]
\end{aligned}
$$

onde $W^{-1}$ é uma matriz de ponderação definida positiva, através da qual as medidas recebem pesos de acordo com o grau de precisão que possuem. É uma matriz diagonal, cujos valores são os inversos das variâncias de cada medida $\left(\sigma_{i i}^{-2}\right)^{2}$.

A minimização da expressão dada por (3.3) é obtida, fazendo-se:

\footnotetext{
${ }^{2}$ Esta informação é fornecida pelos fabricantes de medidores.
} 
$\frac{\partial J(\underline{x})}{\partial \underline{x}}=0$

portanto

$H^{t}(\underline{\hat{x}}) W^{-1}[\underline{z}-h(\underline{\hat{x}})]=0$

onde $H(\underline{\hat{x}})$ é a matriz Jacobiana, dada por:

$H(\underline{\hat{x}})=\left.\frac{\partial h(\underline{x})}{\partial \underline{x}}\right|_{\underline{\hat{x}}}$

Como podemos ver, a solução da equação (3.5) fornece o estado estimado $\underline{\hat{x}}$. Devido à não linearidade de $H(\underline{\hat{x}})$ e $h(\underline{\hat{x}})$, a solução direta dessa equação não é possível. Assim, o estado estimado $\underline{\hat{x}}$ é obtido através de técnicas iterativas. Para isso, utiliza-se o método de Newton-Raphson.

Expandindo em série de Taylor a equação $h(\underline{x})$, e tomando apenas os termos lineares em torno de um ponto inicial $\underline{x}^{0}$, têm-se:

$\underline{h}(\underline{x}) \cong \underline{h}\left(\underline{x}^{0}\right)+H\left(\underline{x}^{0}\right) \Delta \underline{x}^{0}$

De (3.1) obtêm-se:

$\underline{z}=\underline{h}\left(\underline{x}^{0}\right)+H\left(\underline{x}^{0}\right) \Delta \underline{x}^{0}+\underline{w}$

Definindo:

$\Delta \underline{z}\left(\underline{x}^{0}\right)=\underline{z}-\underline{h}\left(\underline{x}^{0}\right)$

Onde $\Delta \underline{z}$ é o erro de estimação, obtendo-se:

$\Delta \underline{z}\left(\underline{x}^{0}\right)=H(\underline{x})^{0} \Delta \underline{x}^{0}+\underline{w}$ 
Assim, a função objetivo passa a ser:

$J(\underline{x})=\left[\Delta \underline{z}\left(\underline{x}^{0}\right)-H\left(\underline{x}^{0}\right) \Delta \underline{x}^{0}\right]^{t} W^{-1}\left[\Delta \underline{z}\left(\underline{x}^{0}\right)-H\left(\underline{x}^{0}\right) \Delta \underline{x}^{0}\right]$

E o mínimo é encontrado fazendo-se:

$H^{t}\left(\underline{x}^{0}\right) W^{-1}\left[\Delta \underline{z}\left(\underline{x}^{0}\right)-H\left(\underline{x}^{0}\right) \Delta \underline{x}^{0}\right]=0$

Portanto:

$$
\left[H^{t}\left(\underline{x}^{0}\right) W^{-1} H\left(\underline{x}^{0}\right)\right] \Delta \underline{x}^{0}=H^{t}\left(\underline{x}^{0}\right) W^{-1} \Delta \underline{z}\left(\underline{x}^{0}\right)
$$

onde a matriz ganho é dada por:

$$
G\left(\underline{x}^{0}\right)=\left[H^{t}\left(\underline{x}^{0}\right) W^{-1} H\left(\underline{x}^{0}\right)\right]
$$

e

$$
\underline{x}^{1}=\underline{x}^{0}+\Delta \underline{x}^{0}
$$

Este processo é repetido até se obter convergência, recalculando-se " $H$ " a cada iteração.

Em geral:

$$
\underline{x}^{v}=\underline{x}^{v-1}+\Delta \underline{x}^{v}
$$

A estimativa de estado $\underline{\hat{x}}$ é o valor de $\underline{x}^{v}$, para uma determinada iteração $v$, em que se verifica um critério de convergência pré fixado. 


\subsection{Detecção e identificação de medidas com erros grosseiros}

Através dos algoritmos baseados na análise dos resíduos (são os mais utilizados), a detecção de erros em medidas analógicas é realizada através do índice $J(\underline{\hat{x}})$, por intermédio de um teste de hipótese.

Considerando a hipótese de que não haja erro grosseiro, o valor do índice $J(\underline{\hat{x}})$, calculado para $\underline{\hat{x}}$ obtido após a convergência do processo de estimação de estados, é comparado com o parâmetro $\beta$. O valor de $\beta$ é previamente determinado, supondo uma distribuição $\chi^{2}$, com (m-n) graus de liberdade ${ }^{3}$ para o índice $J(\underline{\hat{x}})$ e fixada uma certa probabilidade $\rho$ de se tomar a decisão errada, rejeitando-se a hipótese quando ela é verdadeira.

Se $J(\underline{\hat{x}})>\beta$, rejeita-se a hipótese de que não haja erro grosseiro, e, se $J(\underline{\hat{x}})<\beta$ aceita-se a mesma.

Se a hipótese de que não haja erro grosseiro for aceita, consideram-se confiáveis os resultados obtidos pelo estimador de estados. Mas, se essa hipótese for rejeitada, importa identificar e eliminar as medidas que estejam com erros grosseiros.

\subsection{Identificação de medidas com erros grosseiros}

O processo de identificação de medidas com erros grosseiros realiza-se através da análise dos resíduos de estimação normalizados. O vetor resíduo de estimação pode ser definido como:

$$
\underline{r}=\underline{z}-h(\underline{\hat{x}})
$$

que pode ser representado também da seguinte forma [HANDSCHIN et al.(1975)]:

\footnotetext{
${ }^{3}$ Lembrando que m e n representam, respectivamente, o número de medidas e variáveis de estado de um sistema de potência.
} 


$$
\underline{r}=\Gamma \underline{w}
$$

onde:

$\underline{w}$ - é o vetor aleatório dos erros das medidas;

$\Gamma$ - é a matriz sensibilidade do resíduo, dada por:

$$
\Gamma=I-H(\underline{\hat{x}})\left[H^{t}(\underline{\hat{x}}) W^{-1} H(\underline{\hat{x}})\right]^{-1} H^{t}(\underline{\hat{x}}) W^{-1}
$$

Sendo I uma matriz identidade.

A matriz covariância do vetor $\underline{r}$ é a matriz $R$ dada por:

$$
R=W-H(\underline{\hat{x}})\left[H^{t}(\underline{\hat{x}}) W^{-1} H(\underline{\hat{x}})\right]^{-1} H^{t}(\underline{\hat{x}})
$$

Considerando $\rho_{i i}$ o elemento (i,i) da matriz $R$, os resíduos normalizados $\tau_{i}$ ficam definidos como:

$$
\tau_{i}=\frac{r_{i}}{\sqrt{\rho_{i i}}}
$$

com $\mathrm{i}=1,2, \ldots \mathrm{m}$.

Sendo $\tau_{i}^{\max }$ o maior resíduo normalizado, se $\tau_{i}^{\max }>\alpha$, a correspondente medida "i" é portadora de EG (usualmente $\alpha=3$ ) [Monticelli (2000)].

Observação 3.1: O método permite identificar uma medida com erro grosseiro de cada vez. Para casos em que existam mais medidas com erros grosseiros, o processo torna-se pesado, pois, para cada medida uma nova estimação será realizada, até não haver medidas com erros grosseiros. Mesmo assim, o método pode falhar, uma vez que a hipótese levantada de que apenas uma medida possui erro geralmente não é real. 


\subsection{Estimador de Estados e Parâmetros baseado nas Equações Normais}

Como mencionado no Capítulo 1, o estimador de estados e parâmetros baseado nas equações normais aumenta o vetor de estados com os parâmetros a serem estimados. Em razão disto, o vetor de estados passa a ser chamado de Vetor de Estados Aumentado $\left(\underline{x}_{\text {Aum }}\right)$.

Considerando este modelo aumentado, a equação (3.1) torna-se:

$$
\underline{Z}=h_{\text {Aum }}\left(\underline{X}_{\text {Aum }}\right)+\underline{w}
$$

O vetor de estados aumentado " $\underline{X}_{\text {Aum }}$ " é estimado de forma recursiva , através do calculo da matriz Jacobiana Aumentada $H_{\text {Aum }}={ }^{\partial h_{a u m}}{ }^{\partial \underline{\partial x}_{\text {Aum }}}$ e da solução do seguinte conjunto de equações:

$\left[H_{\text {aum }}\right]^{t}[W]\left[H_{\text {Aum }}\right] \cdot \Delta_{\text {Aum }}=\left[H_{\text {Aum }}\right]^{t} \cdot[W] \cdot\left[\underline{z}-h\left(\underline{x}_{\text {Aum }}\right)\right]$

Sendo

$G_{\text {Aum }}=\left[H_{\text {aum }}\right]^{t}[W]\left[H_{\text {Aum }}\right]$

a matriz Ganho Aumentada.

Neste trabalho, vamos considerar que os parâmetros a serem estimados são as condutâncias $\left(G_{k m}\right)$ e as susceptâncias $\left(B_{k m}\right)$ série das linhas de transmissão, bem como as suas susceptâncias shunt $\left(B_{k m}^{s h}\right)$. Conseqüentemente, para um sistema com "L" ramos e "nb" barras, temos " $N=2 n b-1+3 L "$ estados aumentados a serem estimados (sendo "nb" magnitudes de tensão; "nb-1" ângulos de tensão e "3L" parâmetros). 


\section{Capítulo 4}

\section{$4 \quad$ Análise de Observabilidade}

Uma das principais etapas do processo de estimação de estados é a análise de observabilidade do sistema, que consiste em verificar se é possível, através das medidas analógicas e virtuais disponíveis, estimar o estado de todas as barras do sistema.

Neste capítulo será apresentado, em linhas gerais, o método para análise e restauração da observabilidade, desenvolvido por BRETAS (1996), que será utilizado como base para o desenvolvimento do método proposto.

Em razão de o método de BRETAS (1996) realizar a análise considerando o modelo linear ${ }^{1}$, também conhecido como modelo ativo ou $\underline{P \theta}$, na primeira seção deste capítulo encontra-se uma análise do chamado desacoplamento do modelo.

\subsection{Desacoplamento do modelo}

O número de estados a serem estimados para um sistema de potência com $\boldsymbol{n} \boldsymbol{b}$ barras é igual a (2nb-1), sendo:

- (nb-1) ângulos de fase, pois o ângulo de uma das barras é considerado como referência angular;

- nb magnitudes de tensão;

\footnotetext{
${ }^{1}$ A maioria dos métodos desenvolvidos para análise e restauração da observabilidade utilizam o modelo linear [MONTICELLI ; WU (1985ab)]
} 
Assim, para realizar a análise de observabilidade de um sistema de potência, é necessário verificar se é possível, através do conjunto de medidas disponível $^{2}$, estimar os seus (2nb-1) estados.

Então, considerando a equação (3.13), um sistema é observável se a correspondente matriz $G$ tem posto igual ao número de estados a serem estimados, isto é:

$$
\operatorname{Posto}(G)=2 n b-1
$$

Entretanto, através do desacoplamento $\underline{P \theta}-\underline{Q V}$, conhecido como desacoplamento do modelo ${ }^{3}$, podemos realizar a análise de observabilidade separadamente, para cada um dos modelos.

Logo, para determinar se o sistema é $\underline{P \theta}$ observável, importa verificar se é possível, considerando apenas as medidas de potência ativa, estimar os ângulos de fase de (nb-1) barras desse sistema.

Da mesma forma, para determinar se o sistema é $\underline{\text { Q }}$ observável, releva verificar se é possível, considerando apenas as medidas de potência reativa e as de magnitude de tensão, estimar as magnitudes de tensão em todas as $\boldsymbol{n} \boldsymbol{b}$ barras desse sistema.

Face ao exposto e considerando a equação (3.13), pode-se afirmar que:

1. Um sistema é $\underline{P \theta}$ observável se:

$$
\operatorname{Posto}\left(G_{\theta}\right)=n b-1
$$

2. Um sistema é $\underline{Q V}$ observável se:

$$
\operatorname{Posto}\left(G_{V}\right)=n b
$$

\footnotetext{
${ }^{2}$ Como já mencionado, usualmente, as medidas disponíveis são: fluxo de potência ativa e reativa nas linhas, injeção de potência ativa e reativa e algumas magnitudes de tensão nos barramentos.

${ }^{3}$ É obtido considerando o fato de as sensibilidades $\frac{\partial \underline{P}}{\partial \underline{\theta}}$ e $\frac{\partial \underline{Q}}{\partial \underline{V}}$ serem mais intensas que as sensibilidades $\frac{\partial \underline{P}}{\partial \underline{V}}$ e $\frac{\partial \underline{Q}}{\partial \underline{\theta}}[$ MONTICELLI (1983)].
} 
Considerando o que se disse, para um sistema em que as medições de potência ativa e reativa são realizadas aos pares, a existência de pelo menos uma medida de magnitude de tensão faz com que o número de variáveis de estado a serem estimadas para o modelo $\underline{Q V}$ seja igual ao do modelo $\underline{P \theta}$. Assim, se tal sistema é $\underline{P \theta}$ observável, será também $Q V$ observável.

Usualmente, nos sistemas de potência as medições de potência ativa e reativa são realizadas aos pares e existe mais de uma medida de magnitude de tensão. Logo, garantindo que o sistema é $\underline{P \theta}$ observável, está garantido que o mesmo será $Q V$ observável, embora a recíproca possa não ser verdadeira.

Assim, restringir a análise ao modelo $\underline{P \theta}$, ou modelo linear, é uma medida conservadora.

Para o modelo linear a equação (3.13), tem a seguinte forma:

$$
H_{P \theta}^{t} W_{P} H_{P \theta} \underline{\theta}=H_{P \theta}^{t} W_{P} Z_{P}
$$

Com

$$
G_{\theta}=H_{P \theta}^{t} \cdot W_{P} \cdot H_{P \theta}
$$

$\log 0$

$$
G_{\theta} \underline{\theta}=H_{P \theta}^{t} \cdot W_{p} \cdot \underline{Z}_{p}
$$

Onde: $G_{\theta}$ é a matriz ganho, correspondente às medidas de potência ativa; $H_{P \theta}$ é a matriz Jacobiana, relacionada apenas às medidas de potência ativa; $\underline{z}_{P}$ é 0 vetor de medidas de potência ativa e $W_{p}$ é a matriz de ponderação das medidas de potência ativa.

De acordo com MONTICELLI; WU (1985ab), um sistema é observável se qualquer fluxo na rede pode ser observado, por algum tipo de indicação no conjunto de medidas. Em outras palavras, se todas as medidas (fluxo e injeção de potência ativa) são zero, então todos os fluxos devem ser zero quando o sistema é observável. Por outro lado, se houver algum fluxo não zero, significa que esse fluxo não recebe informação das medidas, ou seja, o ramo correspondente a esse fluxo é não observável.

Para o modelo linear, o fluxo de potência ativa, da barra k para a barra 
m, é dado pela seguinte expressão:

$$
P_{k m}=\frac{\theta_{k}-\theta_{m}}{x_{k m}}
$$

Assim, para " $P_{k m}$ " ser nulo é necessário que $\theta_{k}=\theta_{m}$.

Considerando essas observações, em MONTICELLI; WU (1985ab) demonstrou-se que, para analisar a observabilidade de um sistema, basta verificar se a solução da equação (4.6); para $\underline{z}_{p}=0$ é do tipo $\theta_{i}=k, i=1,2 \ldots n b$, isto é, basta verificar se há uma única referência de ângulo de tensão quando $G_{\theta} \underline{\theta}=\underline{0}$.

\subsection{Análise de observabilidade, baseada na fatoração triangular da matriz Ganho e em conceitos de caminhos de fatoração}

A seguir, apresentam-se algumas propriedades demonstradas em BRETAS (1996) e MONTICELLI; WU (1985ab).

Propriedade 1: Se o sistema é observável, a fatoração da matriz $G_{\theta}$, dada pela equação (4.5), quando não se define nenhum ângulo de fase como referência, resulta em somente um caminho de fatoração conexo [BRETAS (1996)]. A matriz $G_{\theta}$, resultante dessa fatoração, apresenta a seguinte forma [BRETAS (1996); MONTICELLI; WU (1985ab)]:

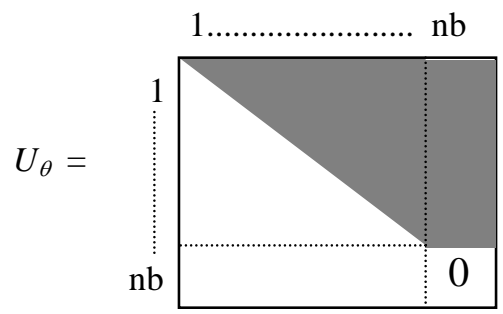

Sendo "nb" o número de barras do sistema (a área escura corresponde aos possíveis elementos não nulos). 
Propriedade 2: Se durante a fatoração de $G_{\theta}$ um pivô zero (PZ) aparecer na diagonal $(i, i)$, sendo $i<n b$, o sistema é não observável como um todo, e os outros elementos da linha e coluna "i" são nulos [MONTICELLI; WU (1985ab)]. Isto significa que os nós restantes, correspondentes às colunas de $U_{\theta}$ de $i+1$ até $n b$, farão parte de outros caminhos de fatoração que não possuíram conexão com o caminho de fatoração anterior [BRETAS (1996)]. A matriz $G_{\theta}$ resultante dessa fatoração terá a seguinte forma [MONTICELLI; WU (1985b)]:

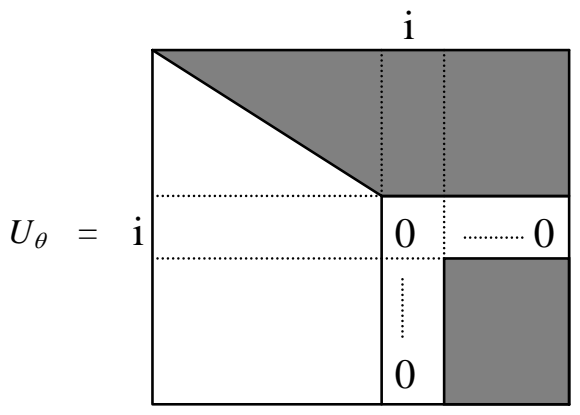

Observação 4.1: Com base nas Propriedade 1 e 2, BRETAS (1996) demonstrou que o número de pivôs nulos encontrados na fatoração da matriz $G_{\theta}$ é igual ao número de caminhos de grafos associados a essa fatoração.

Propriedade 3: Identificação das ilhas observáveis: se na fatoração triangular de $G_{\theta}$ existir mais de um caminho de grafo, podem ocorrer duas situações:

i) Não havendo medidas de injeção de potência ${ }^{4}$ relacionando nós de diferentes caminhos de grafos, o sistema como um todo é não observável e cada sub-rede associada a cada caminho de grafo isolado constitui-se em uma ilha observável da rede [BRETAS (1996)];

ii) Havendo medidas de injeção de potência relacionando nós de diferentes caminhos de grafo, o sistema como um todo é não observável, e não é possível assegurar que as subredes associadas com cada caminho de grafo isolado constituem ilhas observáveis. Para encontrar as ilhas observáveis, aquelas medidas devem ser identificadas e descartadas ${ }^{5}$ para a obtenção da nova matriz $G_{\theta}$. Em seguida essa matriz deve ser fatorada.

\footnotetext{
${ }^{4}$ Dá a informação da potência líquida gerada/consumida por uma determinada barra.

${ }^{5}$ Essas medidas são medidas irrelevantes no que diz respeito a estimação de estados das ilhas observáveis.
} 
O processo de descarte de medidas e de fatoração termina quando não existir medida de injeção relacionando nós de diferentes caminhos de grafo. Cada sub-rede associada a um caminho da grafo isolado constituirá uma ilha observável [BRETAS (1996)].

\subsubsection{Algoritmo para Análise de Observabilidade}

É apresentado a seguir o algoritmo desenvolvido em BRETAS (1996) para análise de observabilidade de redes.

\section{ALGORITMO:}

PASSO 1: com o conjunto de medidas disponível montar a matriz Jacobiana $H_{\theta}$.

PASSO 2: obter a matriz ganho $G_{\theta}$.

PASSO 3: realizar a fatoração triangular da matriz ganho $G_{\theta}$.

PASSO 4: encontrar os caminhos de fatoração associados com a fatoração triangular da matriz ganho $G_{\theta}$. Se apenas um caminho de grafo for encontrado, a rede é observável como um todo, pare. Caso contrário, a rede como um todo é não observável.

\subsubsection{Algoritmo para Identificação de Ilhas Observáveis}

Também em BRETAS (1996), um algoritmo para identificação de ilhas observáveis foi apresentado.

PASSO 1: Na medida em que se obtém mais de um caminho de grafo associado à fatoração triangular da matriz ganho $G_{\theta}$, e:

a) Não existam medidas de injeção de potência relacionando nós de diferentes caminhos de grafos, então as sub-redes associadas com cada caminho de grafo já constituem ilhas observáveis, pare.

b) Existam medidas de injeção de potência relacionando nós de diferentes caminhos de grafos, então nada poderá ser dito a 
respeito da observabilidade das redes associadas com estes caminhos de grafos. Vá para o passo 2.

PASSO 2: Identificar essas medidas e removê-las do conjunto de medidas original. Estas são medidas irrelevantes em termos de estimação de estados.

PASSO 3: Atualizar a matriz ganho $G_{\theta}$ e refazer a fatoração triangular.

PASSO 4: Identificar os caminhos de fatoração e retornar ao passo 1.

Observação 4.2: O algoritmo pode se tornar um processo iterativo no caso de acontecer a situação $b$ do passo 1. A razão disto é que quando medidas irrelevantes são identificadas e descartadas, outras medidas irrelevantes podem aparecer.

\subsection{Exemplo}

\section{Exemplo 1}

O sistema na figura abaixo será usado para mostrar como o algoritmo de análise de observabilidade e o de identificação de ilhas observáveis funcionam.

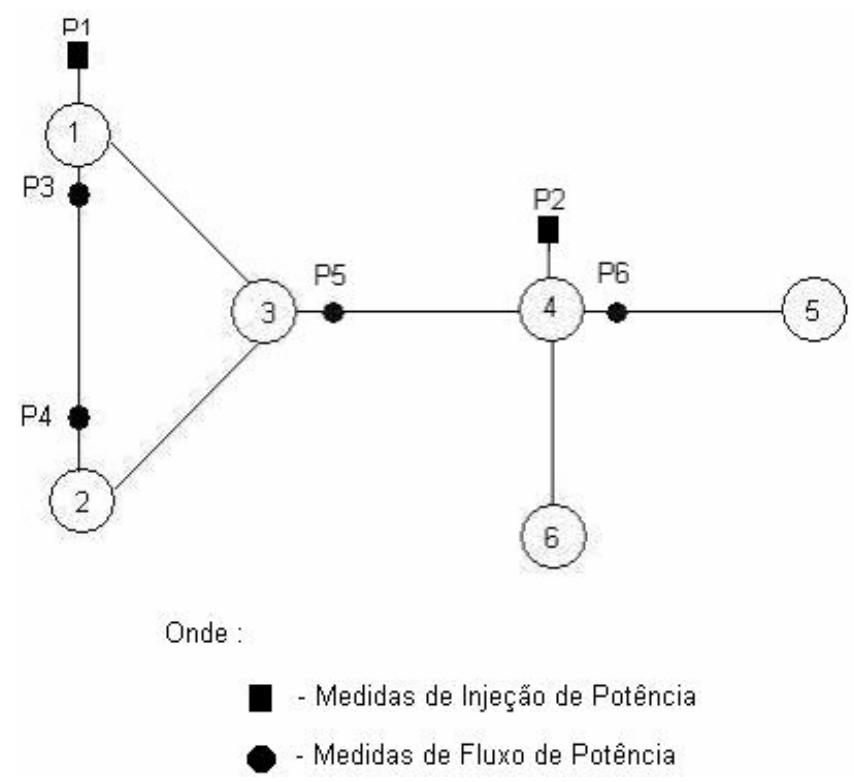

Figura 4.1: Sistema de 6 barras utilizado como exemplo.

Conjunto de medidas: [P1, P2, P3, P4, P5, P6]. AGORITMO PARA ANÁLISE DE OBSERVABILIDADE:

Passo 1: A partir do conjunto de medidas disponível, montar a matriz 
Jacobiana. Para facilitar o cálculo, as reatâncias das linhas são consideradas unitárias, bem como os fatores da matriz de ponderação $W^{-1}$.

$$
H_{\theta}=\begin{array}{r}
P 1 \\
P 2 \\
P 4 \\
P 5 \\
P 6
\end{array}\left[\begin{array}{rrrrrr}
2 & -1 & -1 & 0 & 0 & 0 \\
0 & 0 & -1 & 3 & -1 & -1 \\
1 & -1 & 0 & 0 & 0 & 0 \\
-1 & 1 & 0 & 0 & 0 & 0 \\
0 & 0 & 1 & -1 & 0 & 0 \\
0 & 0 & 0 & 1 & -1 & 0
\end{array}\right]
$$

Passo 2: Obter a matriz Ganho.

$$
G_{\theta}=\left[\begin{array}{rrrrrr}
6 & -4 & -2 & 0 & 0 & 0 \\
-4 & 3 & 1 & 0 & 0 & 0 \\
-2 & 1 & 3 & -4 & 1 & 1 \\
0 & 0 & -4 & 11 & -4 & -3 \\
0 & 0 & 1 & -4 & 2 & 1 \\
0 & 0 & 1 & -3 & 1 & 1
\end{array}\right]
$$

Passo 3: Fazer a fatoração triangular da matriz $G_{\theta}$.

$$
U_{\theta}=\left[\begin{array}{rrrrrr}
1 & -0.67 & -0.33 & 0 & 0 & 0 \\
0 & 1 & -1 & 0 & 0 & 0 \\
0 & 0 & 1 & -2 & 0.5 & 0.5 \\
0 & 0 & 0 & 1 & -0.67 & -0.33 \\
0 & 0 & 0 & 0 & 1 & -1 \\
0 & 0 & 0 & 0 & 0 & 0
\end{array}\right]
$$

Passo 4: Identificar os caminhos de fatoração.

Os caminhos de fatoração são obtidos através da análise dos elementos não 
nulos do triângulo superior da matriz $U_{\theta}$. Percorre-se a linha (i), a partir do elemento (i, i), até o primeiro elemento não nulo (i, j) e passa-se para a próxima linha. O processo é repetido até à penúltima linha da matriz $U_{\theta}$.

Voltando para a matriz $U_{\theta}$, temos:

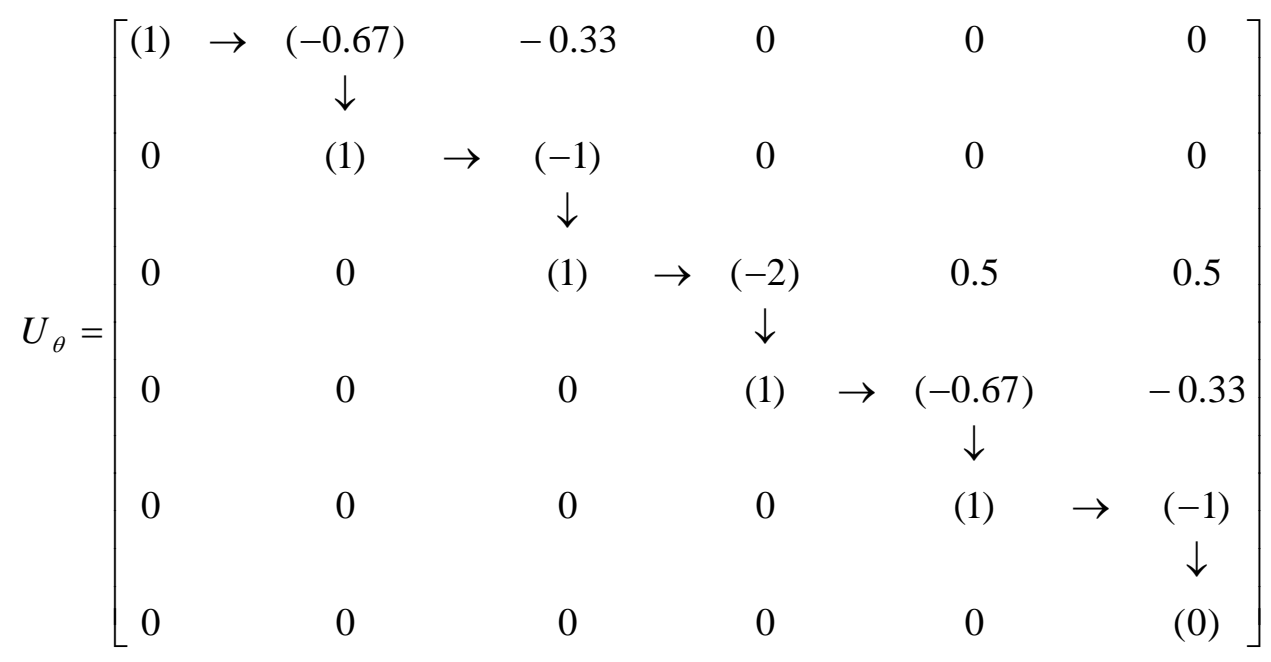

Verificam-se as seguintes conexões ${ }^{6}$ :

Linha 1: elementos [1, 1] e [1, 2] - barra 1 conectada com a barra 2.

Linha 2: elementos [2, 2] e [2, 3] - barra 2 conectada com a barra 3.

Linha 3: elementos [3, 3] e [3, 4] - barra 3 conectada com a barra 4.

Linha 4: elementos $[4,4]$ e $[4,5]$ - barra 4 conectada com a barra 5.

Linha 5: elementos $[5,5]$ e $[5,6]$ - barra 5 conectada com a barra 6 .

O caminho de fatoração associado com a matriz $U_{\theta}$ é mostrado, graficamente, através do caminho de grafo da figura 4.2 .

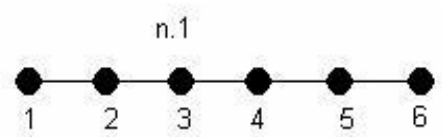

Figura 4.2: Caminho de grafo associado com a matriz $U_{\theta}$

Existe apenas um caminho de fatoração associado com a fatoração triangular da matriz $G_{\theta}$, o caminho $\mathbf{n} \mathbf{1}$. Assim, de acordo com a propriedade 1,

\footnotetext{
${ }^{6}$ Os elementos [i, i] e [i ,j] indicam a existência de conexão entre as barras correspondentes às suas colunas, isto é, conexão entre as barras "i”" e "j”".
} 
o sistema é observável como um todo, com relação ao conjunto de medidas disponível.

\section{Exemplo 2}

Outro exemplo com o mesmo sistema será mostrado, mas com um conjunto de medidas diferente.

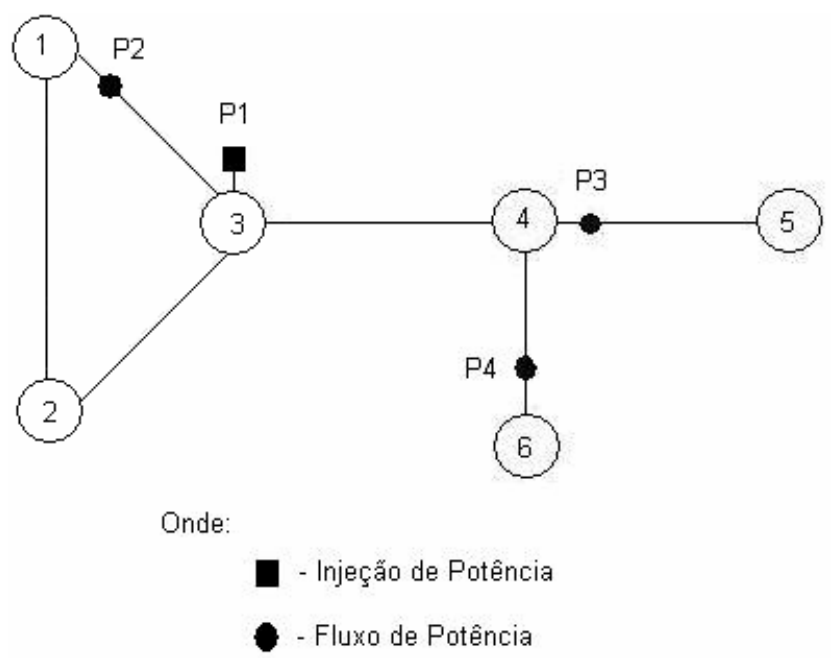

Figura 4.3: Rede de 6 barras

Conjunto de medidas: [P1, P2, P3, P4].

\section{AGORITMO PARA ANÁLISE DE OBSERVABILIDADE:}

Passo 1: Obter a matriz Jacobiana.

$$
H_{\theta}=\begin{array}{r}
P 1 \\
P 3 \\
P 4
\end{array}\left[\begin{array}{rrrrrr}
0 & 0 & -1 & 3 & -1 & -1 \\
1 & 0 & -1 & 0 & 0 & 0 \\
0 & 0 & 0 & 1 & -1 & 0 \\
0 & 0 & 0 & -1 & 0 & 1
\end{array}\right]
$$

Passo 2: Obter a Matriz Ganho. 


$$
G_{\theta}=\left[\begin{array}{rrrrrr}
2 & 1 & -4 & 1 & 0 & 0 \\
1 & 1 & -3 & 1 & 0 & 0 \\
-4 & -3 & 10 & 3 & 0 & 0 \\
1 & 1 & -3 & 3 & -1 & -1 \\
0 & 0 & 0 & -1 & 1 & 0 \\
0 & 0 & 0 & -1 & 0 & 1
\end{array}\right]
$$

Passo 3: Fazer a fatoração triangular da matriz $G_{\theta}$.

$$
U_{\theta}=\left[\begin{array}{rrrrrr}
1 & 0.5 & -2 & 0.5 & 0 & 0 \\
0 & 1 & -2 & 1 & 0 & 0 \\
0 & 0 & 0 & 0 & 0 & 0 \\
0 & 0 & 0 & 1 & -0.5 & -0.5 \\
0 & 0 & 0 & 0 & 1 & -1 \\
0 & 0 & 0 & 0 & 0 & 0
\end{array}\right]
$$

Passo 4: Identificar os caminhos de fatoração.

Como no exemplo anterior, verificam-se as seguintes conexões:

Linha 1: elementos $[1,1]$ e [1, 2] - barra 1 conectada com a barra 2.

Linha 2: elementos [2, 2] e [2, 3] - barra 2 conectada com a barra 3.

Linha 3: barra 3 não tem conexão com as barras 4, 5 e 6 (linha de zeros) .

Linha 4: elementos $[4,4]$ e $[4,5]$ - barra 4 conectada com a barra 5.

Linha 5: elementos $[5,5]$ e $[5,6]$ - barra 5 conectada com a barra 6 .

Os caminhos de fatoração associados com a matriz $U_{\theta}$ são mostrados, graficamente, através dos caminhos de grafo da figura 4.4.
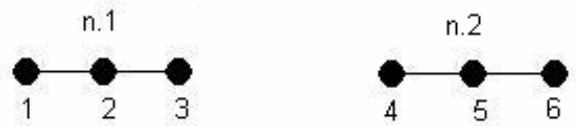

Figura 4.4: Caminhos de grafo associados com a matriz $U_{\theta}$.

Neste caso aparecem dois caminhos de fatoração associados com a 
fatoração triangular, o caminho n1 e o caminho n2.

De acordo com a propriedade 3, chega-se a conclusão de que o sistema é não observável como um todo, com relação ao conjunto de medidas disponíveis.

A partir deste ponto importa identificar as ilhas observáveis do sistema.

\section{AGORITMO PARA IDENTIFICAÇÃO DE ILHAS OBSERVÁVEIS:}

Passo 1: Através dos caminhos de fatoração, verificar se existem medidas de injeção relacionando nós de diferentes caminhos de fatoração.

Medidas:

- Medida P1: relaciona os nós 3 e 4 que estão em caminhos de fatoração diferentes.

Passo 2: Remover essa(s) medida(s).

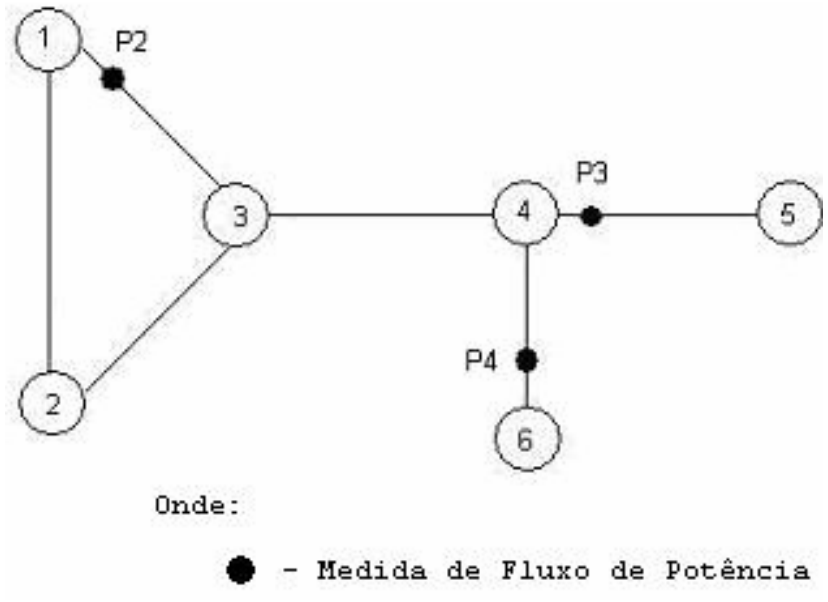

Figura 4.5 Rede de 6 barras utilizada

Conjunto de medidas atualizado: [P2, P3, P4].

Passo 3: Atualizar a matriz $G_{\theta}$ e refazer fatoração triangular. 


$$
U_{\theta}^{D C}=\left[\begin{array}{rrrrrr}
1 & 0 & -1 & 0 & 0 & 0 \\
0 & 0 & 0 & 0 & 0 & 0 \\
0 & 0 & 0 & 0 & 0 & 0 \\
0 & 0 & 0 & 1 & -0.5 & -0.5 \\
0 & 0 & 0 & 0 & 1 & -1 \\
0 & 0 & 0 & 0 & 0 & 0
\end{array}\right]
$$

Passo 4: Identificar caminhos de fatoração.

Linha 1: elementos $[1,1]$ e $[1,3]$ - barra 1 conectada com a barra 3.

Linha 2: barra 2 não tem conexão com as barras 3, 4, 5 e 6 (linha de zeros) .

Linha 3: barra 3 não tem conexão com as barras 4, 5 e 6 (linha de zeros) .

Linha 4: elementos $[4,4]$ e $[4,5]$ - barra 4 conectada com a barra 5.

Linha 5: elementos $[5,5]$ e $[5,6]$ - barra 5 conectada com a barra 6 .

Os caminhos de fatoração associados com a matriz $U_{\theta}$ são mostrados, graficamente, através dos caminhos de grafo da figura 4.6

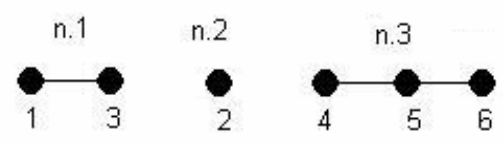

Figura 4.6: Caminhos de grafo associados com a matriz $U_{\theta}$.

Neste caso aparecem três caminhos de fatoração associados com a fatoração triangular de $G_{\theta}$.

Passo 1: Através dos caminhos de fatoração, verificar se existem medidas de injeção relacionando nós de diferentes caminhos de grafos.

Como não existe medida de injeção relacionando nós de caminhos de grafos distintos, de acordo com a propriedade 3 , chega-se a conclusão de que o sistema não é observável como um todo e as sub-redes associadas com cada caminho de fatoração isolado constituem ilhas observáveis. 
Observação 4.3: Além dos algoritmos apresentados nesta seção, em Bretas (1996) apresenta-se um algoritmo para restaurar a observabilidade do sistema. 


\section{Capítulo 5}

5 Método para Análise de Observabilidade para o Modelo Aumentado

\subsection{Introdução}

Propõe-se neste capítulo um método para análise de observabilidade para o modelo aumentado, isto é, para o estimador de estados e parâmetros baseado nas equações normais ${ }^{1}$ [PEREIRA et al. (2004)].

O método proposto é uma extensão do método desenvolvido por Bretas (1996), apresentado no capítulo anterior, que se destina à análise de observabilidade para o estimador de estados convencional.

\subsection{Análise de observabilidade para o modelo aumentado}

O método para análise de observabilidade desenvolvido por BRETAS (1996) se baseia na fatoração triangular da matriz ganho $(G)$ e em conceitos de caminhos de fatoração. Em razão de o método proposto ser uma extensão desse método, ele se baseia na fatoração triangular da matriz $G_{A u m}$ e em conceitos de caminhos de fatoração.

\footnotetext{
${ }^{1}$ A formulação do estimador de estados e parâmetros baseado nas equações normais foi apresentada no capítulo 3.
} 


\subsubsection{Estrutura da matriz Ganho Aumentada}

Considerando a formulação do estimador de estados e parâmetros, baseado nas equações normais, apresentada no Capítulo 3, a matriz Jacobiana Aumentada $\left(H_{\text {Aum }}\right)$ tem a seguinte estrutura:

$$
H_{A u m}=\left[\begin{array}{lll}
H_{P \theta} & H_{P v} & H_{P p} \\
H_{Q \theta} & H_{q v} & H_{Q p} \\
H_{V \theta} & H_{V v} & H_{V p}
\end{array}\right]=\left[\begin{array}{lll}
\frac{\partial P}{\partial \theta} & \frac{\partial P}{\partial v} & \frac{\partial P}{\partial p} \\
\frac{\partial Q}{\partial \theta} & \frac{\partial Q}{\partial v} & \frac{\partial Q}{\partial p} \\
\frac{\partial V}{\partial \theta} & \frac{\partial V}{\partial v} & \frac{\partial V}{\partial p}
\end{array}\right]
$$

Onde: "P", "Q" e "V" indicam respectivamente o vetor de medidas de potência ativa, reativa e medidas de magnitude de tensão; " $\theta$ ", "v" e "p", indicam respectivamente os vetores de ângulo de tensão, magnitude de tensão e parâmetros do sistema. A matriz Ganho Aumentada $\left(G_{\text {Aum }}\right)$, dada pela equação 3.24 , tem a seguinte forma:

$$
G_{\text {Aum }}=\left[H_{\text {Aum }}\right]^{t}[W]^{-1}\left[H_{\text {Aum }}\right]=\left[\begin{array}{ccc}
G_{\theta} & G_{\theta v} & G_{\theta p} \\
G_{v \theta} & G_{v} & G_{v p} \\
G_{p \theta} & G_{p v} & G_{p}
\end{array}\right]
$$

Onde:

$$
\begin{aligned}
& G_{\theta}=\left[H_{P \theta}\right]^{T}\left[W_{P}\right]\left[H_{P \theta}\right]+\left[H_{Q \theta}\right]^{T}\left[W_{Q}\right]\left[H_{Q \theta}\right]+\left[H_{V \theta}\right]^{T}\left[W_{V}\right]\left[H_{V \theta}\right] \\
& G_{\theta_{v}}=\left[H_{P \theta}\right]^{T}\left[W_{P}\right]\left[H_{P V}\right]+\left[H_{Q \theta}\right]^{T}\left[W_{Q}\right]\left[H_{Q V}\right]+\left[H_{V \theta}\right]^{T}\left[W_{V}\right]\left[H_{V v}\right] \\
& G_{\theta p}=\left[H_{P \theta}\right]^{T}\left[W_{P}\right]\left[H_{P p}\right]+\left[H_{Q \theta}\right]^{T}\left[W_{Q}\right]\left[H_{Q p}\right]+\left[H_{V \theta}\right]^{T}\left[W_{V}\right]\left[H_{V p}\right] \\
& G_{v \theta}=\left[H_{P v}\right]^{T}\left[W_{P}\right]\left[H_{P \theta}\right]+\left[H_{Q v}\right]^{T}\left[W_{Q}\right]\left[H_{Q \theta}\right]+\left[H_{V V}\right]^{T}\left[W_{V}\right]\left[H_{V \theta}\right] \\
& G_{v}=\left[H_{P v}\right]^{T}\left[W_{P}\right]\left[H_{P v}\right]+\left[H_{Q v}\right]^{T}\left[W_{Q}\right]\left[H_{Q v}\right]+\left[H_{V v}\right]^{T}\left[W_{V}\right]\left[H_{V v}\right]
\end{aligned}
$$




$$
\begin{aligned}
& G_{v p}=\left[H_{P v}\right]^{T}\left[W_{P}\right]\left[H_{P p}\right]+\left[H_{Q v}\right]^{T}\left[W_{Q}\right]\left[H_{Q p}\right]+\left[H_{V v}\right]^{T}\left[W_{V}\right]\left[H_{V p}\right] \\
& G_{p \theta}=\left[H_{P p}\right]^{T}\left[W_{P}\right]\left[H_{P \theta}\right]+\left[H_{Q p}\right]^{T}\left[W_{Q}\right]\left[H_{Q \theta}\right]+\left[H_{V p}\right]^{T}\left[W_{V}\right]\left[H_{V \theta}\right] \\
& G_{p v}=\left[H_{P p}\right]^{T}\left[W_{P}\right]\left[H_{P v}\right]+\left[H_{Q p}\right]^{T}\left[W_{Q}\right]\left[H_{Q v}\right]+\left[H_{V p}\right]^{T}\left[W_{V}\right]\left[H_{V v}\right] \\
& G_{p}=\left[H_{P p}\right]^{T}\left[W_{P}\right]\left[H_{P p}\right]+\left[H_{Q p}\right]^{T}\left[W_{Q}\right]\left[H_{Q p}\right]+\left[H_{V p}\right]^{T}\left[W_{V}\right]\left[H_{V p}\right]
\end{aligned}
$$

Observação 5.1: Neste trabalho considera-se que as medidas de potência são realizadas aos pares e que existe uma medida de magnitude de tensão em cada barra do sistema.

Dado um conjunto de medidas e considerando a teoria apresentada no Capítulo 4, as seguintes situações podem ocorrer quando se faz a análise de observabilidade para o modelo aumentado.

\section{1) Sistema observável como um todo}

O conjunto de medidas disponível possibilita a estimação de todo o vetor de estados aumentado (magnitudes e ângulos de tensão nas barras e parâmetros do sistema). Para um sistema observável como um todo a fatoração triangular da matriz $G_{\text {Aum }}$, quando não se define um ângulo de referência, resulta em somente um pivô zero $(\mathrm{PZ})$ na posição $U_{\text {Aum }}(n b, n b)$. Nesta situação existe apenas um caminho de fatoração associado à submatriz $U_{\theta}$ de $U_{\text {Aum }}$ e todos os estados aumentados são observáveis. A matriz $G_{\text {Aum }}$ fatorada assume a seguinte forma:

[colocar as propriedades] 


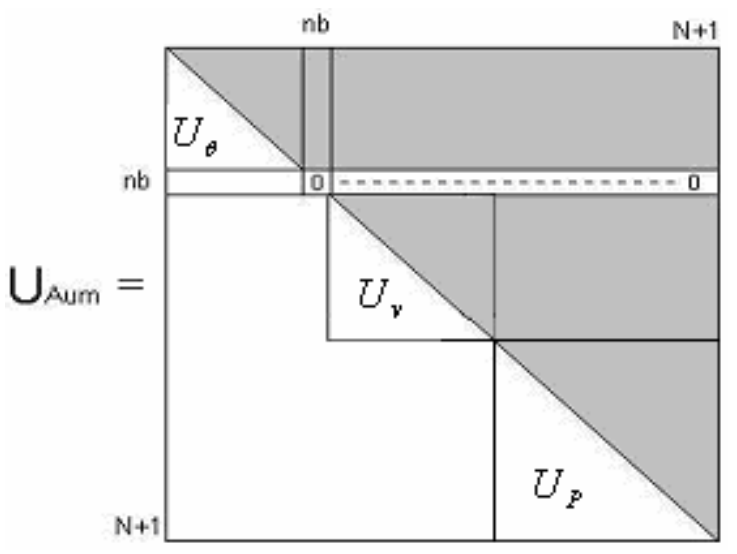

Figura 5.1: Matriz $G_{\text {Aum }}$ fatorada (situação 1)

Observação 5.2: A parte escura corresponde aos possíveis elementos não nulos

\section{2) Sistema $\theta V$ - observável}

O conjunto de medidas disponível possibilita a estimação de todos os estados " $\theta$ " e "v" do vetor de estados aumentados, mas não para todos os parâmetros do sistema, tais parâmetros são denominados não observáveis. Quando um sistema é $\underline{\underline{\theta V}}$ - observável, temos:

- a fatoração triangular da matriz $G_{\text {Aum }}$, quando não se define um ângulo de referência, resulta em mais de um PZ, mas apenas um destes está contido na sub-matriz $U_{\theta}$ de $U_{\text {Aum }}$, isto é, existe apenas um caminho de fatoração associado com essa sub-matriz. Os demais PZs estarão contidos na sub-matriz $U_{P}$, de $U_{A u m}$, e correspondem aos parâmetros não observáveis;

- não existe nenhuma medida de potência relacionando os parâmetros não observáveis.

A matriz $G_{\text {Aum }}$ fatorada assume a seguinte forma: 


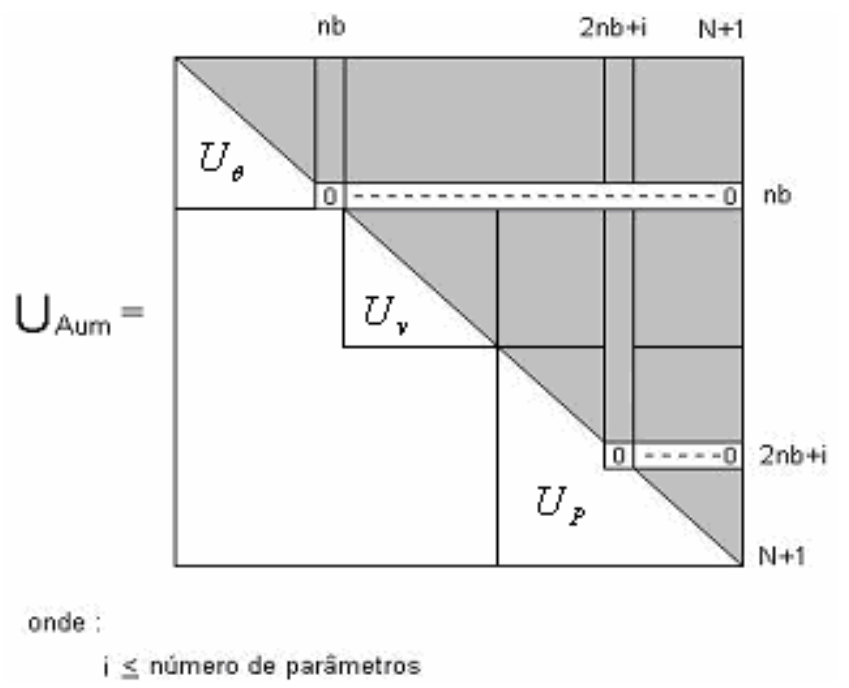

Figura 5.2: Matriz $G_{\text {Aum }}$ fatorada (situação 2). Sistema $\theta V$ - observável.

\section{3) Sistema não observável}

O conjunto de medidas disponível não possibilita a estimação de todos os estados aumentados, nem mesmo de todos os estados $\theta$ e v. Isto é, o sistema não é observável como um todo, nem mesmo $\theta \mathrm{V}$ - observável.

Para um sistema não observável, a fatoração triangular da matriz $G_{\text {Aum }}$ resulta em mais de um PZ na sub-matriz $U_{\theta}$ de $U_{\text {Aum }}$, e a matriz $G_{\text {Aum }}$ fatorada assume a seguinte forma:

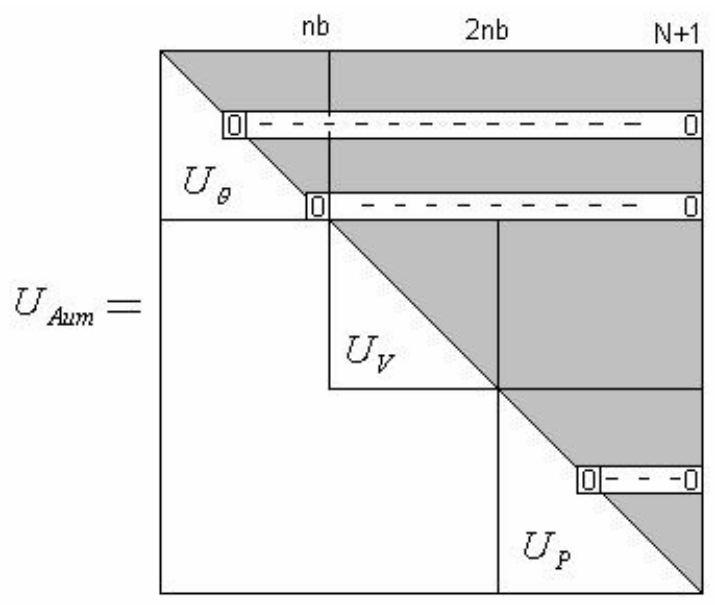

Figura 5.3: Matriz $G_{\text {Aum }}$ fatorada (situação 3). Sistema não observável. 
Quando um sistema é não observável, é necessário identificar as ilhas observáveis.

Para o modelo aumentado temos dois tipos de ilhas observáveis:

Ilha observável como um todo:

O conjunto de medidas associado a essa ilha possibilita a estimação de todos os seus estados aumentados.

Ilha $\theta \mathrm{V}$ - observável:

O conjunto de medidas associado a essa ilha possibilita a estimação de todos os seus estados $\theta$ e v, mas não de todos os seus parâmetros.

Observação 5.3: Podem ainda existir ilhas formadas por apenas uma barra. São barras isoladas da rede que não serão consideradas pelo estimador de estados e parâmetros ${ }^{2}$.

\subsection{Algoritmo}

Baseando-se na seção anterior e na teoria apresentada em Bretas (1996), descrita sumariamente no capítulo anterior, propõe-se o seguinte algoritmo para análise de observabilidade para o modelo aumentado. Importa destacar que caso o sistema não seja observável como um todo, nem mesmo $\theta V$ - observável, o algoritmo permite a identificação das ilhas observáveis.

\section{ALGORITMO:}

Passo 1: Obter a matriz $G_{A u m}$;

Passo 2: Realizar a fatoração triangular da matriz $G_{\text {Aum }}$. Se aparecer apenas um PZ, o sistema é observável como um todo; PARE. Caso contrário, vá para o próximo passo;

Passo 3: Identificação dos parâmetros não observáveis: estes parâmetros correspondem aos PZs que apareceram na fatoração de $G_{A u m}$, da diagonal "2nb+1" até " $\mathrm{N}+1{ }^{3}{ }^{3}$ (sub-matriz $U_{P}$ );

Passo 4: Se não existir medidas de injeção ou fluxo de potência relacionando

\footnotetext{
${ }^{2}$ Essas ilhas também aparecem para o modelo convencional.

${ }^{3}$ Conforme definido na página 18 do capítulo 3 “N” é o número de estados aumentados a serem estimados.
} 
os parâmetros não observáveis, identifique os caminhos de fatoração associados com a sub-matriz $U_{\theta}$ de $U_{\text {Aum }}$. Se o número de caminhos de fatoração for igual a 1, o sistema é $\theta V$-observável. Ou, se for maior, o sistema é não observável e cada caminho de grafo isolado constitui uma ilha observável ou $\theta V$-observável (de acordo com as observações no item 5.2); pare. Caso contrário, vá para o próximo passo;

Observação 5.4: Se não existir medidas de potência relacionando os parâmetros não observáveis, como esses parâmetros são incidentes aos ramos do sistema, pode-se afirmar que não existem medidas de potência relacionando os nós de diferentes caminhos de grafo. Conseqüentemente, cada caminho de grafo constitui, de acordo com a propriedade 3 (Capítulo 4), uma ilha observável como um todo ou $\theta \mathrm{V}$-observável .

Passo 5: Elimine todas as medidas de injeção e de fluxo de potência que relacionam os parâmetros não observáveis ${ }^{4}$. Obter a nova matriz $G_{\text {Aum }}$ e, em seguida, fatorar essa matriz. Volte ao passo 3.

Uma vez determinadas as ilhas observáveis, realiza-se a estimação de estados e parâmetros separadamente para cada uma das ilhas.

Observação 5.5: Realiza-se a análise de observabilidade através da matriz $G_{\text {Aum }}$ obtida na primeira iteração do processo de estimação de estados e parâmetros.

\subsection{Exemplo}

Serão apresentados, nesta seção, quatro exemplos da aplicação do método proposto. No primeiro exemplo o sistema é observável como um todo, não sendo necessária a identificação de ilhas observáveis. No segundo o sistema é $\theta V$-observável, onde identificam-se os parâmetros não observáveis. No terceiro exemplo o sistema é não observável, sendo necessária a

\footnotetext{
${ }^{4}$ Essas medidas são irrelevantes no que diz respeito à estimação de estados e parâmetros das ilhas observáveis.
} 
identificação das ilhas observáveis. Por fim, no quarto exemplo, o sistema é não observável, sendo necessária a identificação das ilhas observáveis, onde uma delas é $\theta V$-observável ${ }^{5}$.

$1^{\circ}$ exemplo: O método é aplicado ao sistema de cinco barras associado ao conjunto de medidas ilustrado na figura 5.4.

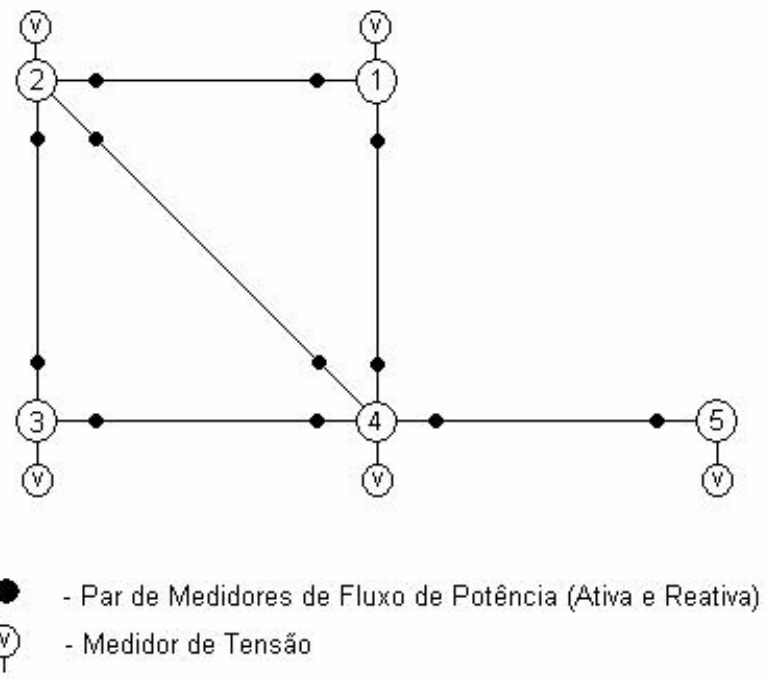

Figura 5.4: Sistema teste de 5 barras

O primeiro passo para realizar a análise de observabilidade é obter a matriz $G_{\text {Aum }}$, dada pela equação 5.2. Para simplificar os cálculos e melhorar o condicionamento da matriz $G_{A u m}$, faz-se:

- $W=I$, sendo $I$ uma matriz identidade ;

- Os valores das tensões complexas e dos parâmetros, necessários para o cálculo são escolhidos de forma a melhorar o condicionamento de $G_{\text {Aum }}{ }^{6}$.

Considerando o conjunto de medidas indicado na figura 5.4, e os valores dos estados aumentados apresentados na tabela 5.1, obtêm-se a matriz $G_{\text {Aum }}$ e faz-se a fatoração triangular da mesma (passos 1 e 2 do algoritmo proposto):

\footnotetext{
${ }^{5}$ Não consideramos medidas de injeção de potência, embora sua inclusão não inviabilizar o método.

${ }^{6}$ Isto pode ser feito, pois o objetivo do algoritmo é a análise de observabilidade e não a estimação de estados e parâmetros.
} 
Tabela 5.1: Estados Aumentados utilizados nos testes (sistema de 5 barras)

Dados de Linha:

\begin{tabular}{|c|c|c|c|c|}
\hline Origem(barra) & Destino(barra) & $\mathrm{G}(\mathrm{pu})$ & $\mathrm{B}(\mathrm{pu})$ & Shunt $(\mathrm{pu})$ \\
\hline 1 & 2 & 0.18 & -0.8 & 0.01 \\
\hline 1 & 4 & 0.17 & -0.7 & 0.015 \\
\hline 2 & 3 & 0.20 & -0.9 & 0.01 \\
\hline 2 & 4 & 0.19 & -0.7 & 0.015 \\
\hline 3 & 4 & 0.18 & -0.8 & 0.01 \\
\hline 4 & 5 & 0.19 & -0.9 & 0.018 \\
\hline
\end{tabular}

Dados de barra:

\begin{tabular}{|c|c|c|}
\hline Barra & Tensão $(\mathrm{pu})$ & Ângulo (rad) \\
\hline 1 & 1.0 & 0.0 \\
\hline 2 & 0.8 & 0.2 \\
\hline 3 & 0.7 & 0.3 \\
\hline 4 & 0.9 & 0.1 \\
\hline 5 & 0.8 & 0.2 \\
\hline
\end{tabular}

A estrutura da $G_{\text {Aum }}$ fatorada é a seguinte:

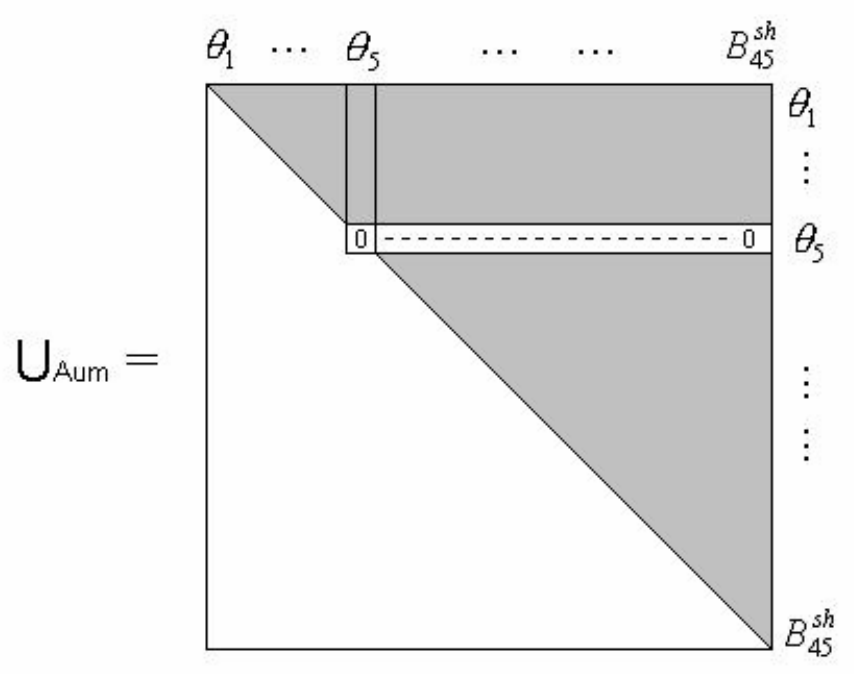

Figura 5.5: Matriz $G_{\text {Aum }}$ fatorada (exemplo 1) 
Como apareceu apenas um PZ (elemento $U_{\text {Aum }}(\theta 5, \theta 5)$ ), o sistema é observável como um todo, com relação ao conjunto de medidas disponível. O caminho de fatoração associado com a sub-matriz $U_{\theta}$ de $U_{\text {Aum }}$ é mostrado, graficamente, através do caminho de grafo abaixo.

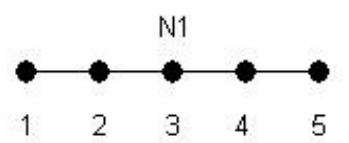

Figura 5.6: Caminho de grafo (exemplo 1)

$2^{\circ}$ exemplo: O método proposto é aplicado ao sistema de 5 barras, associado ao conjunto de medidas ilustrado na figura 5.7.

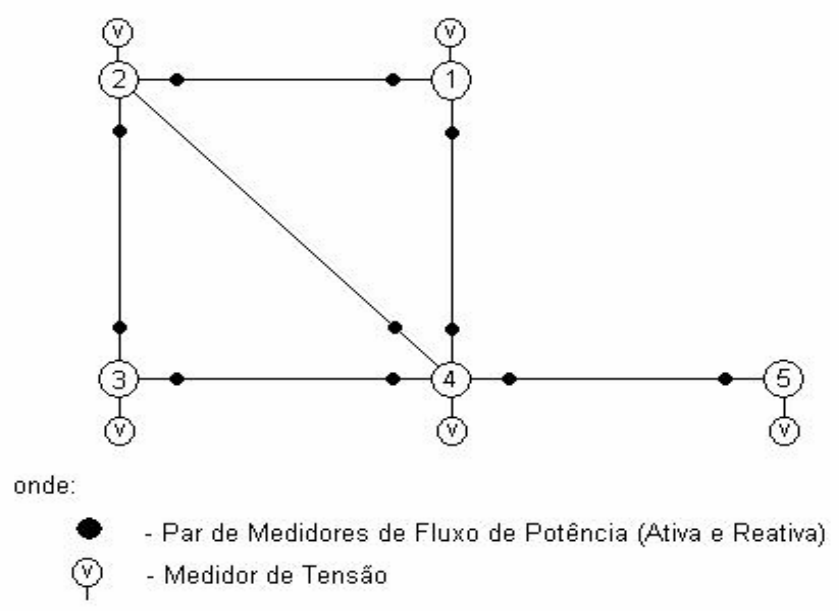

Figura 5.7: Sistema em teste 5 barras.

Considerando o conjunto de medidas indicado na figura 5.7 (medidas $P_{24}$ e $Q_{24}$ foram retiradas), e os valores dos estados aumentados apresentados na tabela 5.1, obtêm-se a matriz $G_{\text {Aum }}$ e faz-se a fatoração triangular da mesma (passos 1 e 2). A estrutura da matriz $G_{\text {Aum }}$ fatorada é apresentada na figura 5.8. 


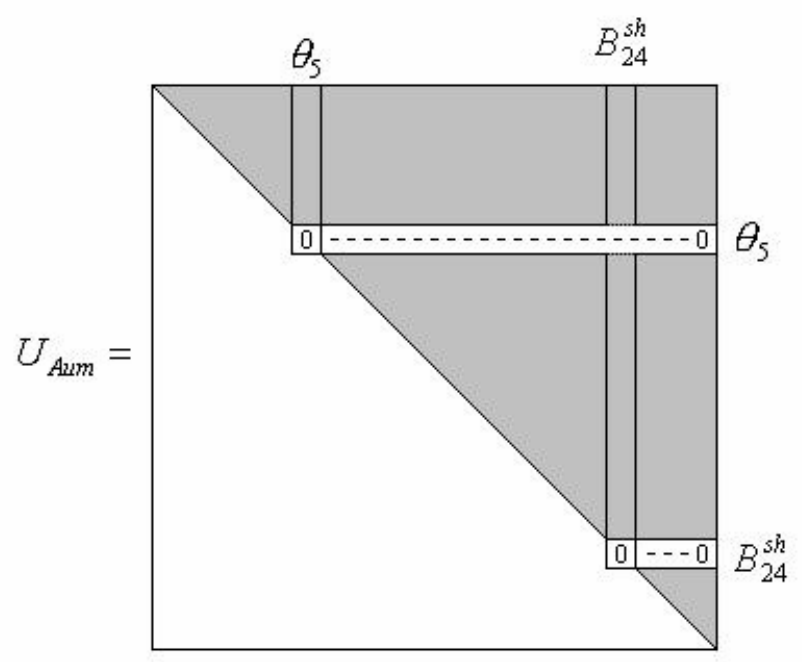

Figura 5.8: Matriz $G_{\text {Aum }}$ fatorada (exemplo 2)

Como existem dois PZs, elementos $U_{\text {Aum }}\left(\theta_{5}, \theta_{5}\right)$ e $U_{\text {Aum }}\left(B_{24}^{s h}, B_{24}^{s h}\right), 0$ sistema não é observável como um todo, vá para o passo 3.

Passo 3: O parâmetro não observável é: $B_{24}^{\text {sh }}$;

Passo 4: As medidas de potência $P_{42}$ e $Q_{42}$ relacionam o parâmetro não observável;

Passo 5: $P_{42}$ e $Q_{42}$ são removidas. A nova $G_{\text {Aum }}$ é obtida e fatorada.

A estrutura da nova matriz $G_{\text {Aum }}$ fatorada é apresentada na figura 5.9:

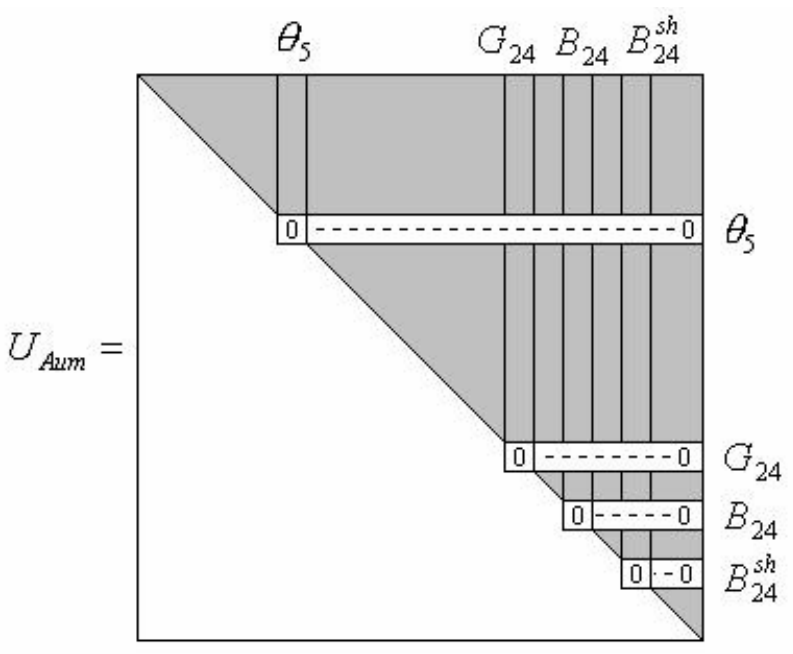

Figura 5.9: Matriz $G_{\text {Aum }}$ fatorada (exemplo 2) 
Existem quatro PZs: $U_{\text {Aum }}\left(\theta_{5}, \theta_{5}\right), \quad U_{\text {Aum }}\left(G_{24}, G_{24}\right), \quad U_{\text {Aum }}\left(B_{24}, B_{24}\right) \quad \mathrm{e}$ $U_{\text {Aum }}\left(B_{24}^{s h}, B_{24}^{s h}\right)$. Volte ao passo 3.

Passo 3: Os parâmetros não observáveis são: $G_{24}, B_{24}$ e $B_{24}^{\text {sh }}$;

Passo 4: Não existe medida de potência relacionando os parâmetros não observáveis; existe apenas um caminho de fatoração associado com a submatriz $\cup_{\theta}$ de $U_{\text {Aum }}$. Assim, o sistema é $\theta V$-observável e os parâmetros do ramo que interliga as barras 2 e 4 são não observáveis.

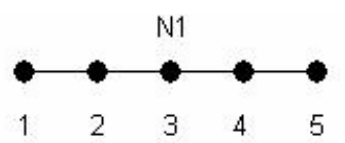

figura 5.10: Caminho de grafo (exemplo 2)

$3^{\circ}$ exemplo: $O$ método proposto é aplicado ao sistema de 5 barras, associado ao conjunto de medidas ilustrado na figura 5.11 .

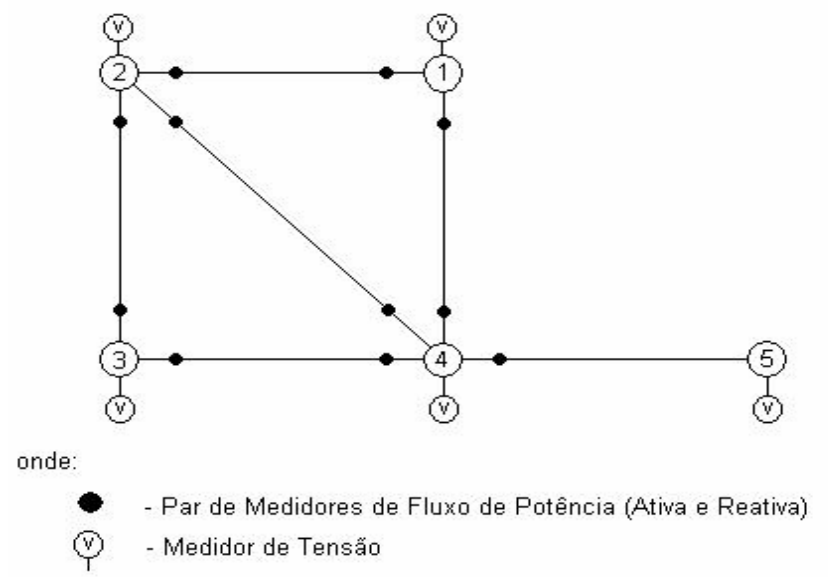

Figura 5.11: Sistema teste de 5 Barras (exemplo 3)

Considerando o conjunto de medidas indicado na figura 5.11(medidas $P_{54}$ e $Q_{54}$ foram retiradas), e os valores dos estados aumentados apresentados na tabela 5.1, obtêm-se a matriz $G_{\text {Aum }}$ e faz-se a fatoração triangular da mesma (passos 1 e 2). A estrutura da matriz $G_{\text {Aum }}$ fatorada é apresentada na figura 5.12 . 


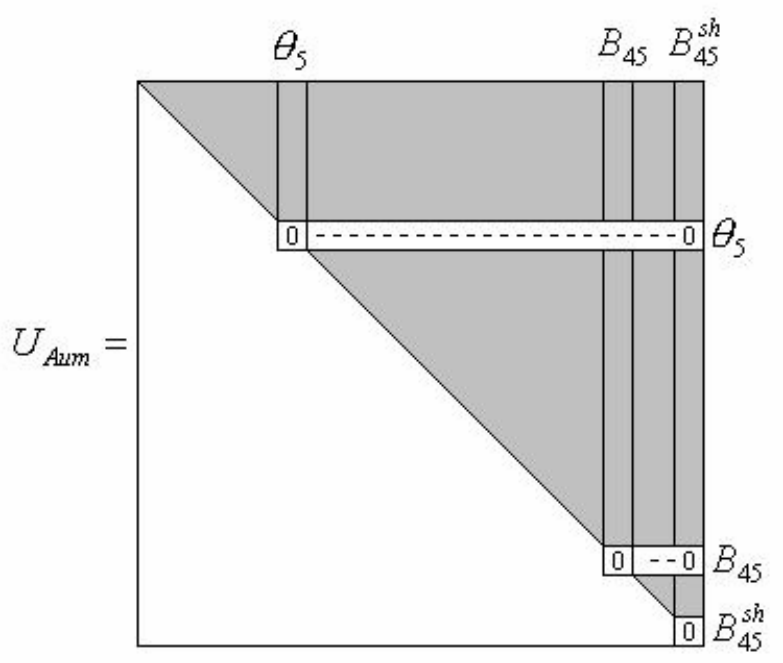

Figura 5.12: Matriz $G_{\text {Aum }}$ fatorada (exemplo 3)

Como existem três PZs, elementos $U_{\text {Aum }}\left(\theta_{5}, \theta_{5}\right), U_{\text {Aum }}\left(B_{45}, B_{45}\right)$ e $U_{A u m}\left(B_{45}^{s h}, B_{45}^{s h}\right)$, o sistema não é observável como um todo. Vá para o passo 3.

Passo 3: Os parâmetros não observáveis são: $B_{45}$ e $B_{45}^{\text {sh }}$;

Passo 4: As medidas de potência $P_{45}$ e $Q_{45}$ relacionam os parâmetros não observáveis;

Passo 5: $P_{42}$ e $Q_{42}$ são removidas. A nova $G_{\text {Aum }}$ é obtida e fatorada.

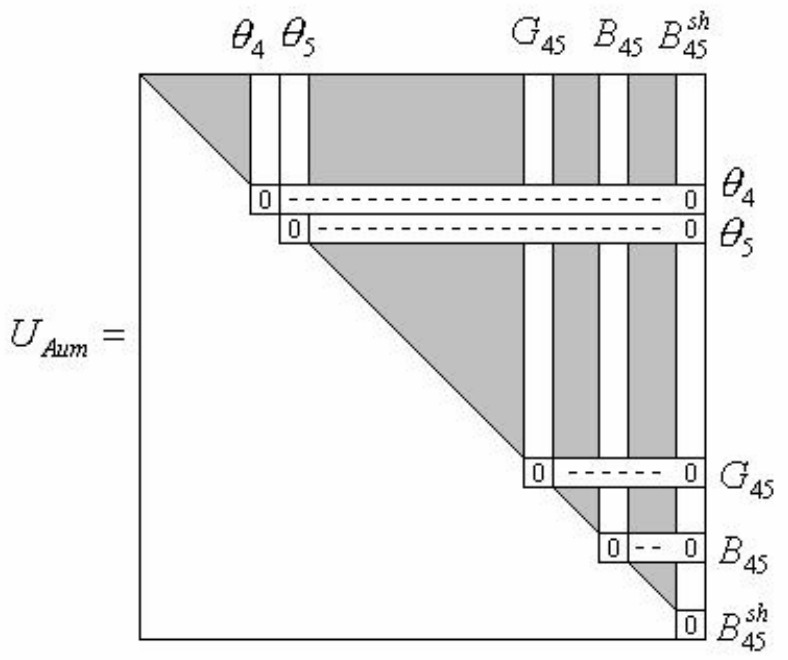

Figura 5.13: Matriz $G_{\text {Aum }}$ fatorada (exemplo 3) 
Como existem cinco PZs, elementos $U_{\text {Aum }}\left(\theta_{4}, \theta_{4}\right), U_{\text {Aum }}\left(\theta_{5}, \theta_{5}\right)$, $U_{\text {Aum }}\left(G_{45}, G_{45}\right), U_{\text {Aum }}\left(B_{45}, B_{45}\right)$ e $U_{A u m}\left(B_{45}^{s h}, B_{45}^{s h}\right)$, o sistema não é observável como um todo. Vá para o passo 3.

Passo 3: Os parâmetros não observáveis são: $G_{45}, B_{45}$ e $B_{45}^{s h}$;

Passo 4: Não existe medida de potência relacionando os parâmetros não observáveis; o número de caminhos de fatoração associados com a submatriz $U_{\theta}$ de $U_{\text {Aum }}$ é igual a 2. A figura 5.14 representa os caminhos de grafo para este exemplo. O caminho de grafo $\mathrm{N} 1$ constitui uma ilha observável como um todo. Já o caminho N2 constitui uma ilha formada por apenas uma barra.

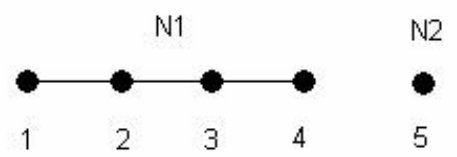

Figura 5.14: Caminhos de Grafos (exemplo 3)

$4^{\circ}$ exemplo: O método proposto é aplicado ao sistema de 5 barras, associado ao conjunto de medidas ilustrado na figura 5.12 .

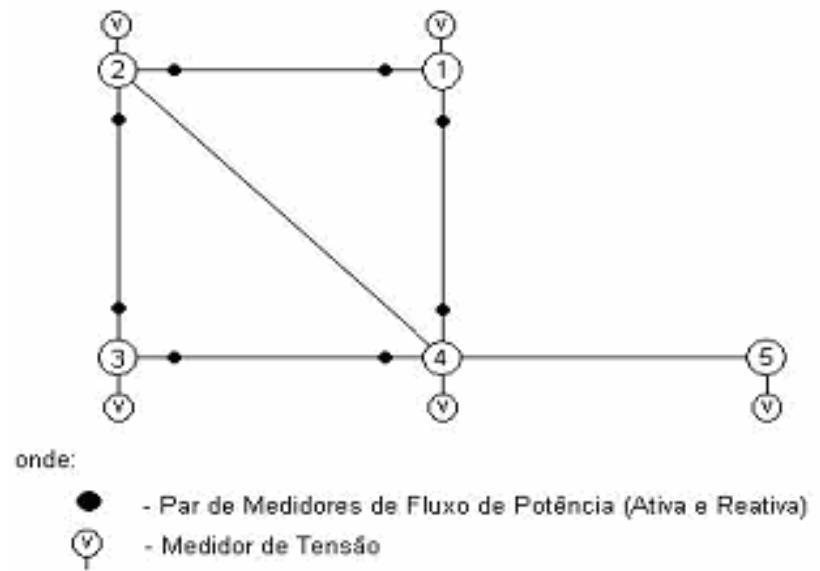

Figura 5.12: Sistema teste de 5 Barras (exemplo 4)

Considerando o conjunto de medidas indicado na figura 5.12 (medidas $P_{24}, Q_{24}, P_{42}, Q_{42}, P_{45}, Q_{45}, P_{54}$ e $Q_{54}$ foram retiradas), e os valores dos estados aumentados apresentados na tabela 5.1 obtêm-se a matriz $G_{\text {Aum }}$ e faz-se a fatoração triangular da mesma (passos 1 e 2). 
Foram encontrados oito PZs, os elementos

$U_{\text {Aum }}\left(\theta_{4}, \theta_{4}\right), U_{\text {Aum }}\left(\theta_{5}, \theta_{5}\right), U_{\text {Aum }}\left(G_{24}, G_{24}\right), U_{\text {Aum }}\left(B_{24}, B_{24}\right), U_{\text {Aum }}\left(B_{24}^{s h}, B_{24}^{s h}\right), U_{\text {Aum }}\left(G_{45}, G_{45}\right)$,

$U_{A u m}\left(B_{45}, B_{45}\right)$ e $U_{A u m}\left(B_{45}^{s h}, B_{45}^{s h}\right)$; o sistema não é observável como um todo. Vá para o passo 3.

Passo 3: Os parâmetros não observáveis são: $G_{24}, B_{24}, B_{24}^{s h}, G_{45}, B_{45}$ e $B_{45}^{s h}$;

Passo 4: Não existe medida de potência relacionando os parâmetros não observáveis; o número de caminhos de fatoração associado com a submatriz $U_{\theta}$ de $U_{\text {Aum }}$ é igual a 2. A figura 5.14 representa os caminhos de grafo para este exemplo. O caminho de grafo $\mathrm{N} 1$ constitui uma ilha $\theta \mathrm{V}$-observável $\left(G_{24}, B_{24}, B_{24}^{s h}\right.$ são não observáveis) e o caminho N2 uma ilha observável formada por apenas uma barra.

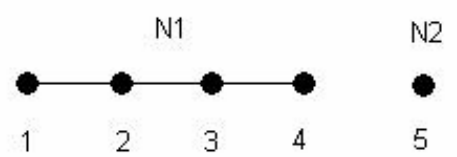

Figura 5.14: Caminhos de Grafos (exemplo 4)

Neste capítulo foram apresentados 4 exemplos de aplicação do método proposto. Os exemplos demonstram a eficácia do método. No próximo capítulo serão apresentados testes realizados com os sistemas de 6,14 e 30 barras do IEEE. 


\section{Capítulo 6}

\section{$6 \quad$ Testes e Análise dos Resultados}

De acordo com o que foi apresentado no capítulo anterior, são apresentados, neste capítulo, testes para comprovar a eficiência do método proposto para análise de observabilidade do modelo aumentado. Os sistemas utilizados para os testes foram: IEEE 6,14 e 30 Barras.

\subsection{Testes com o sistema de 6 barras do IEEE}

\section{Teste 1}

O método é aplicado ao sistema de 6 barras, associado ao conjunto de medidas ilustrado na figura 6.1. Os valores dos estados aumentados utilizados nos testes, estão na tabela 6.1 


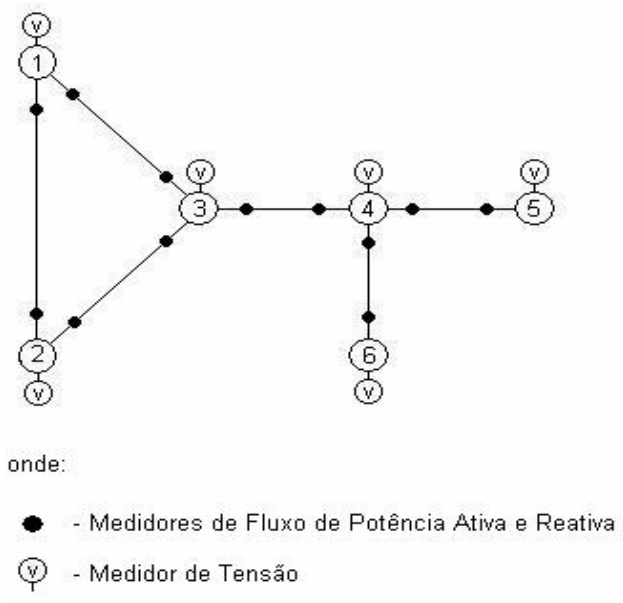

Figura 6.1: Sistema teste de 6 barras (teste 1)

Tabela 6.1: Dados do sistema de 6 barras

Dados de Linha:

\begin{tabular}{|c|c|c|c|c|}
\hline Origem(barra) & Destino(barra) & $\mathrm{G}(\mathrm{pu})$ & $\mathrm{B}(\mathrm{pu})$ & Shunt(pu) \\
\hline 1 & 2 & 0.18 & -0.8 & 0.01 \\
\hline 1 & 3 & 0.17 & -0.7 & 0.015 \\
\hline 2 & 3 & 0.17 & -0.8 & 0.01 \\
\hline 3 & 4 & 0.18 & -0.7 & 0.015 \\
\hline 4 & 5 & 0.18 & -0.8 & 0.01 \\
\hline 4 & 6 & 0.17 & -0.7 & 0.015 \\
\hline
\end{tabular}

Dados de Barra:

\begin{tabular}{|c|c|c|}
\hline Barra & Tensão $(\mathrm{pu})$ & Ângulo $(\mathrm{rad})$ \\
\hline 1 & 1.0 & 0.0 \\
\hline 2 & 0.8 & 0.2 \\
\hline 3 & 0.7 & 0.3 \\
\hline 4 & 0.9 & 0.14 \\
\hline 5 & 0.7 & 0.2 \\
\hline 6 & 0.72 & 0.3 \\
\hline
\end{tabular}

Obtêm-se a matriz $G_{\text {Aum }}$ e faz-se a fatoração triangular da mesma. A estrutura da matriz $G_{\text {Aum }}$ fatorada é apresentada na figura 6.2: 


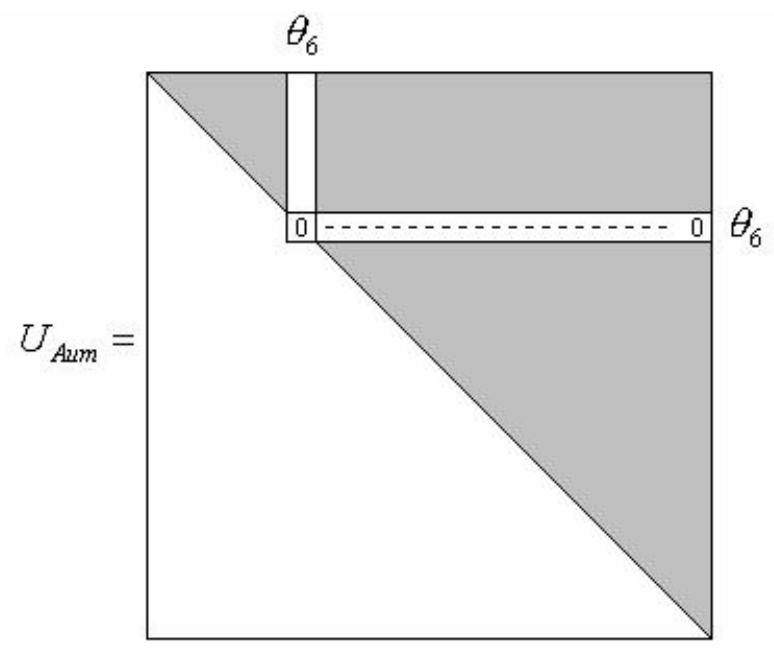

Figura 6.2: Matriz $G_{\text {Aum }}$ fatorada (teste 1)

Como apareceu somente um PZ (elemento $U_{A u m}\left(\theta_{6}, \theta_{6}\right)$ ), o sistema é observável como um todo, com relação ao conjunto de medidas disponível. $\mathrm{O}$ caminho de fatoração associado com a submatriz $U_{\theta}$ de $U_{\text {Aum }}$ é mostrado, graficamente, através do caminho de grafo apresentado na figura 6.3.

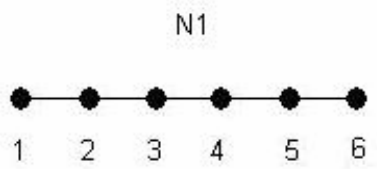

Figura 6.3: Caminho de grafo (teste 1) 


\section{Teste 2}

O método é aplicado ao sistema de seis barras, associado com o conjunto de medidas ilustrado na figura 6.4.

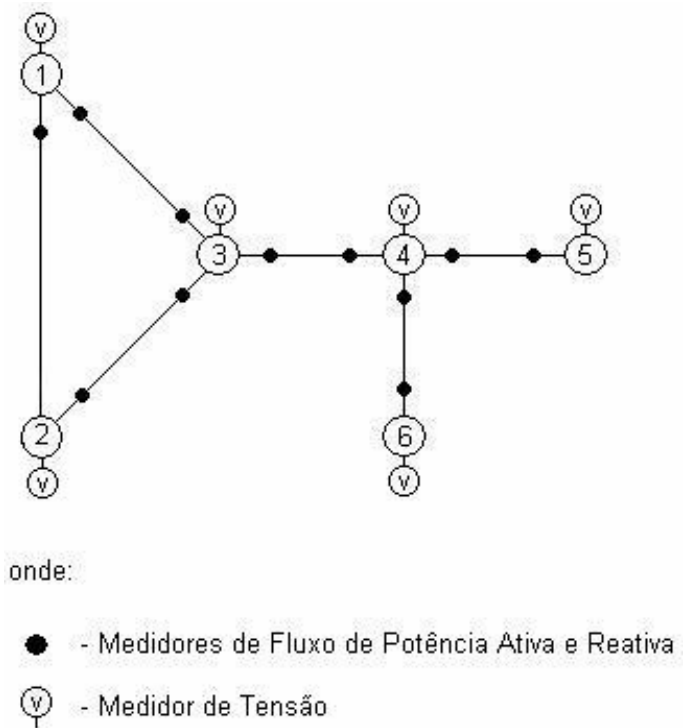

Figura 6.4: Rede de 6 barras (teste 2)

Considerando o conjunto de medidas indicado na figura 6.4 ( medidas $P_{21}$ e $Q_{21}$ foram retiradas), e os valores dos estados aumentados, apresentados na tabela 6.1, obtem-se a matriz $G_{\text {Aum }}$ e faz-se a fatoração triangular da mesma (passos 1 e 2 do algoritmo proposto). A estrutura da matriz $G_{\text {Aum }}$ fatorada é apresentada na figura 6.5.

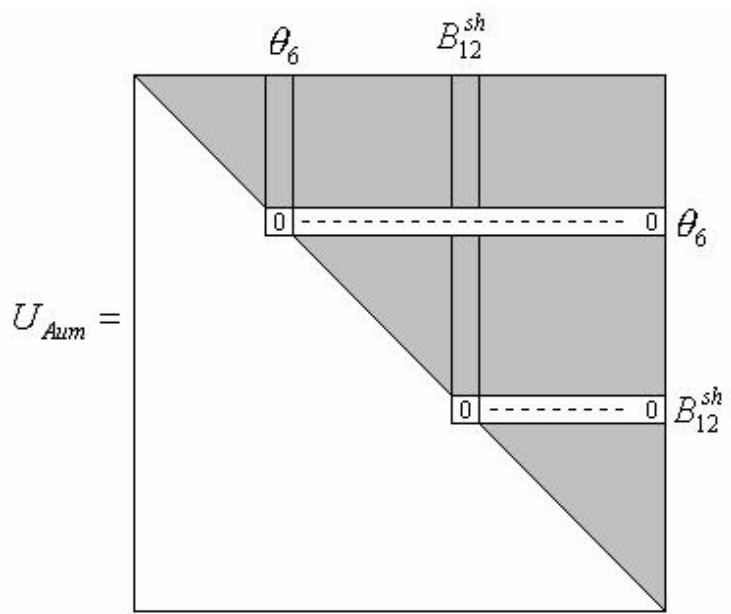

Figura 6.5: Matriz $G_{\text {Aum }}$ fatorada (teste 2) 
Como existem dois PZs $\left(U_{\text {Aum }}\left(\theta_{6}, \theta_{6}\right)\right.$ e $\left.U_{A u m}\left(B_{12}^{s h}, B_{12}^{s h}\right)\right)$, o sistema é não observável como um todo. Vá para o passo 3.

Passo 3: Parâmetro não observável: $B_{12}^{\text {sh }}$;

Passo 4: As medidas $P_{12}$ e $Q_{12}$ relacionam o parâmetro não observável;

Passo 5: $P_{12}$ e $Q_{12}$ são removidas. A nova matriz $G_{\text {Aum }}$ é obtida e fatorada.

A estrutura da matriz $G_{\text {Aum }}$ fatorada é apresentada na figura 6.6:

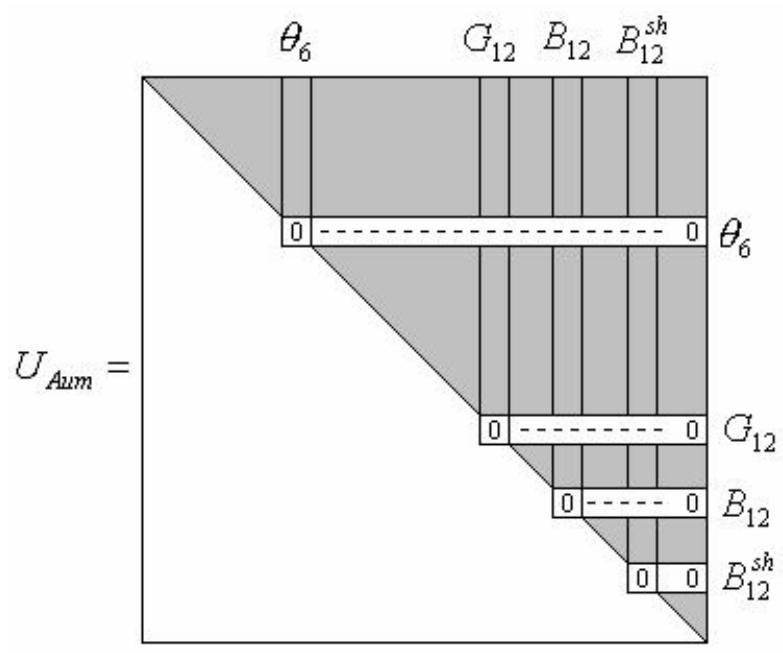

Figura 6.6: Matriz $G_{\text {Aum }}$ fatorada (teste 2)

Existem quatro PZs: $U_{\text {Aum }}\left(\theta_{6}, \theta_{6}\right), \quad U_{\text {Aum }}\left(G_{12}, G_{12}\right), \quad U_{\text {Aum }}\left(B_{12}, B_{12}\right)$ e $U_{\text {Aum }}\left(B_{12}^{s h}, B_{12}^{s h}\right)$; volte ao passo 3 .

Passo 3: Parâmetros não observáveis: $G_{12}, B_{12}$ e $B_{12}^{\text {sh }}$;

Passo 4: Não existe medida de potência relacionando os parâmetros não observáveis; existe apenas um caminho de fatoração associado com a submatriz $U_{\theta}$ de $U_{\text {Aum }}$; o sistema é $\theta V$-observável, e o ramo que interliga as barras 1 e 2 é não observável.

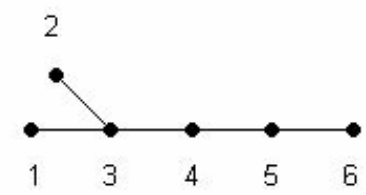

Figura 6.7: Caminho de grafo (teste 2) 


\section{Teste 3}

O método é aplicado ao sistema de seis barras, associado ao conjunto de medidas ilustrado na figura 6.8.

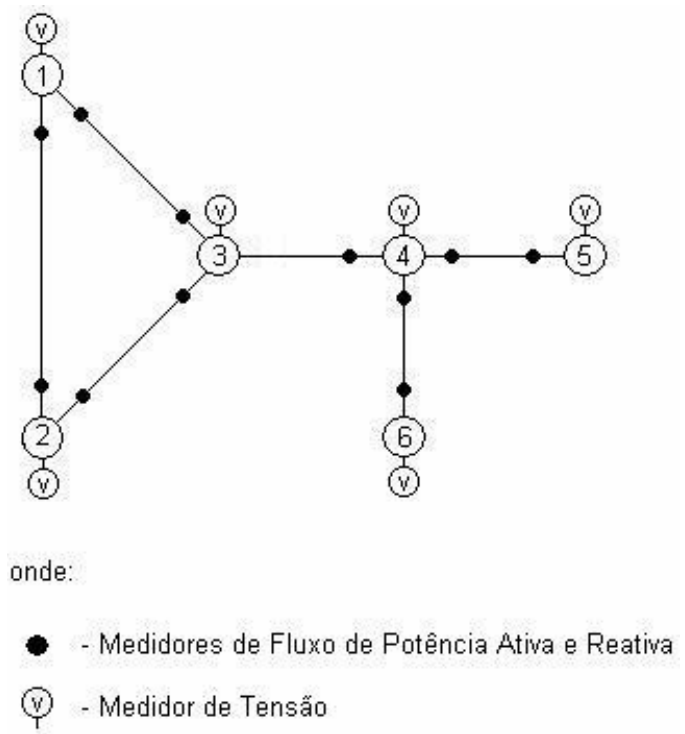

Figura 6.8: Rede de 6 barras (teste 3)

Considerando o conjunto de medidas indicado na figura 6.8 ( medidas $P_{34} \quad$ e $Q_{34}$ foram retiradas), e os valores dos estados aumentados, apresentados na tabela 6.1, obtem-se a matriz $G_{\text {Aum }}$ e faz-se a fatoração triangular da mesma (passos 1 e 2). A estrutura da matriz $G_{\text {Aum }}$ fatorada é apresentada na figura 6.9.

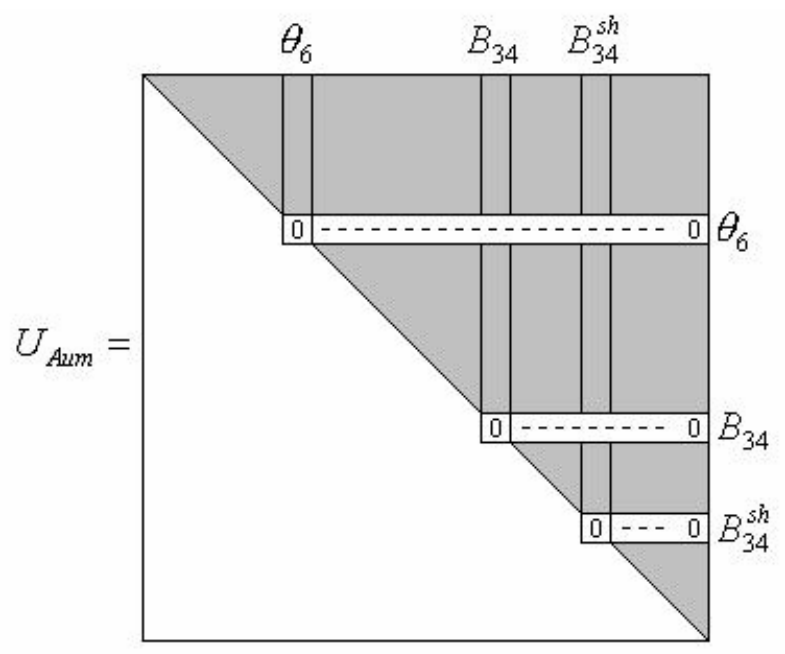

figura 6.9: Matriz $G_{\text {Aum }}$ fatorada (teste 3) 
Como existem três PZs $\left(U_{\text {Aum }}\left(\theta_{6}, \theta_{6}\right), U_{A u m}\left(B_{34}, B_{34}\right)\right.$ e $\left.U_{A u m}\left(B_{34}^{s h}, B_{34}^{s h}\right)\right)$, o sistema é não observável como um todo. Vá para o passo 3.

Passo 3: Parâmetros não observáveis: $B_{34}^{\text {sh }}$ e $B_{34}$;

Passo 4: As medidas $P_{43}$ e $Q_{43}$ relacionam os parâmetros não observáveis;

Passo 5: $P_{43}$ e $Q_{43}$ são removidas. A nova matriz $G_{\text {Aum }}$ é obtida e fatorada.

A estrutura da nova matriz $G_{\text {Aum }}$ fatorada fica:

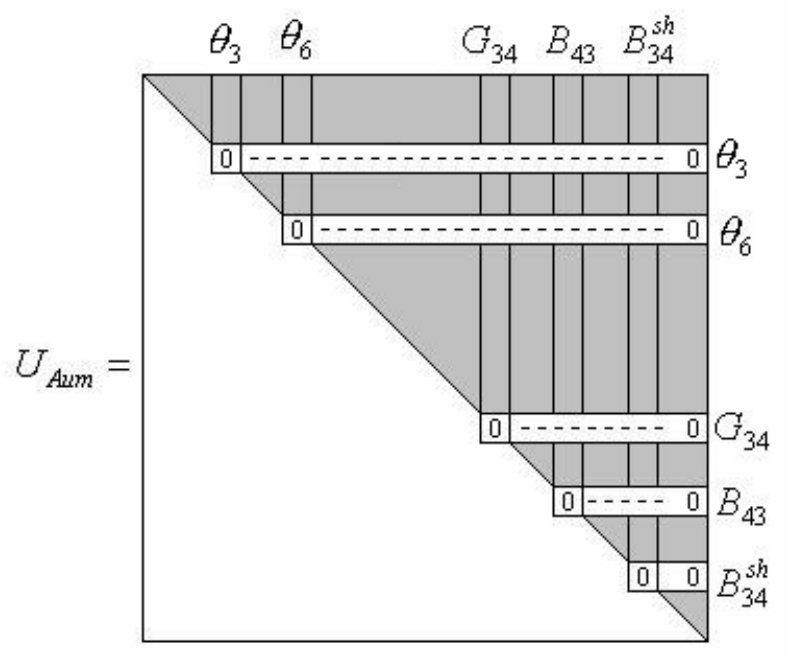

Figura 6.10: Matriz $G_{\text {Aum }}$ fatorada (teste 3)

Existem cinco PZs: $\quad U_{\text {Aum }}\left(\theta_{3}, \theta_{3}\right), \quad U_{\text {Aum }}\left(\theta_{6}, \theta_{6}\right), \quad U_{\text {Aum }}\left(G_{34}, G_{34}\right)$, $U_{\text {Aum }}\left(B_{34}, B_{34}\right)$ e $U_{A u m}\left(B_{34}^{s h}, B_{34}^{s h}\right)$, volte ao passo 3.

Passo 3: Parâmetros não observáveis: $G_{34}, B_{34}$ e $B_{34}^{\text {sh }}$;

Passo 4: Não existe medida de potência relacionando os parâmetros não observáveis; existem dois caminhos de fatoração associados com a submatriz $U_{\theta}$ de $U_{\text {Aum }}$; o sistema é não observável como um todo, e o ramo que interliga as barras 3 e 4 é não observável. Sendo assim, temos duas ilhas observáveis como um todo, representadas, graficamente, através dos caminhos de grafos mostrados na figura 6.11 . 


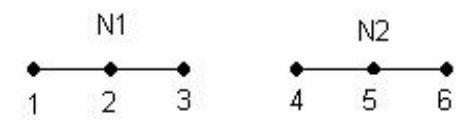

Figura 6.11: Caminhos de grafo (teste 3)

\subsection{Testes com o sistema de 14 barras do IEEE}

\section{Teste 4}

O método é aplicado ao sistema de 14 barras, associado com o conjunto de medidas ilustrado na figura 6.12. Os valores dos estados aumentados, utilizados nos testes, estão na tabela 6.2.

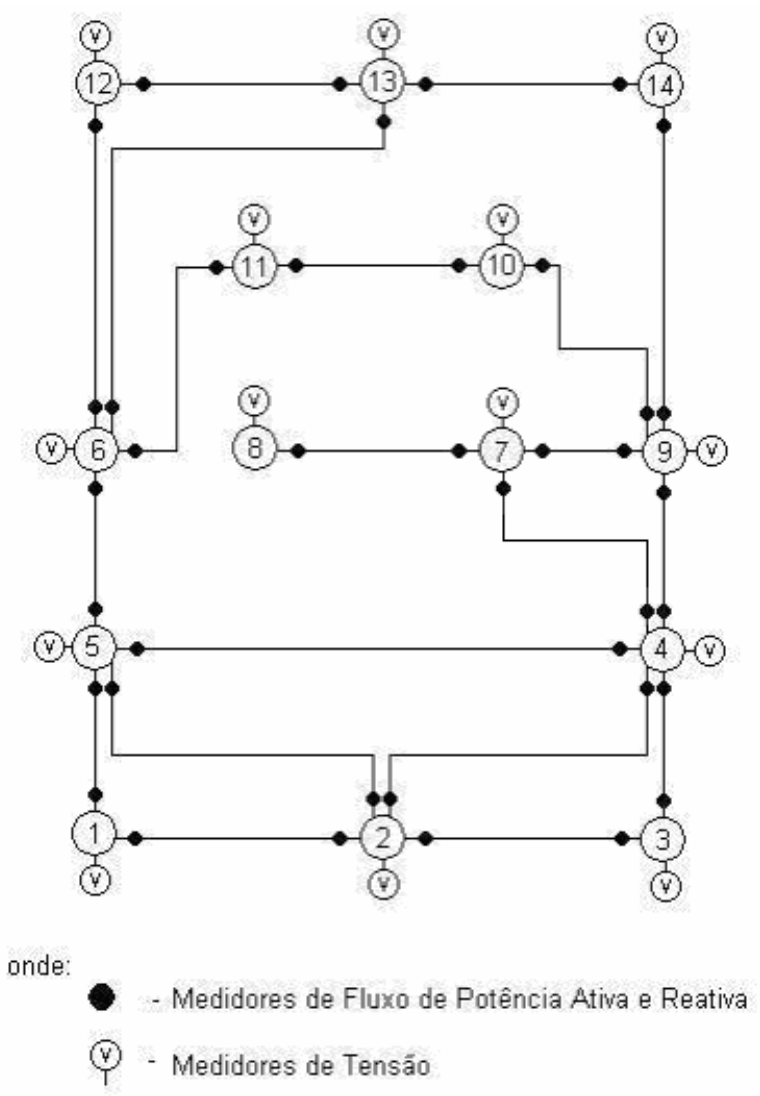

Figura 6.12: Sistema de 14 barras do IEEE 
Tabela 6.2: Estados Aumentados utilizados nos testes (14 barras)

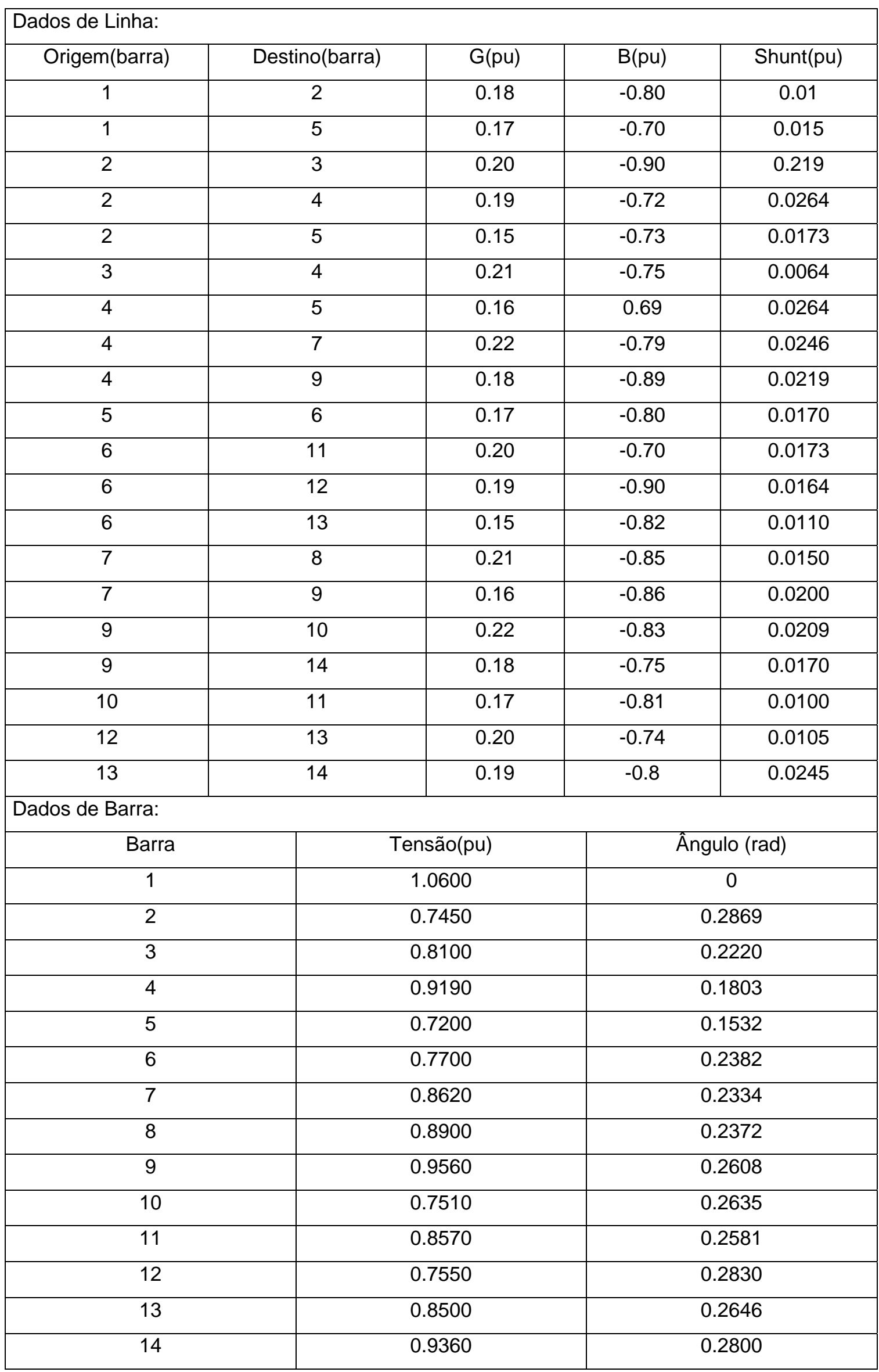


Obtêm-se a matriz $G_{\text {Aum }}$ e faz-se a fatoração triangular da mesma (passos 1 e 2). A estrutura da matriz $G_{\text {Aum }}$ fatorada fica:

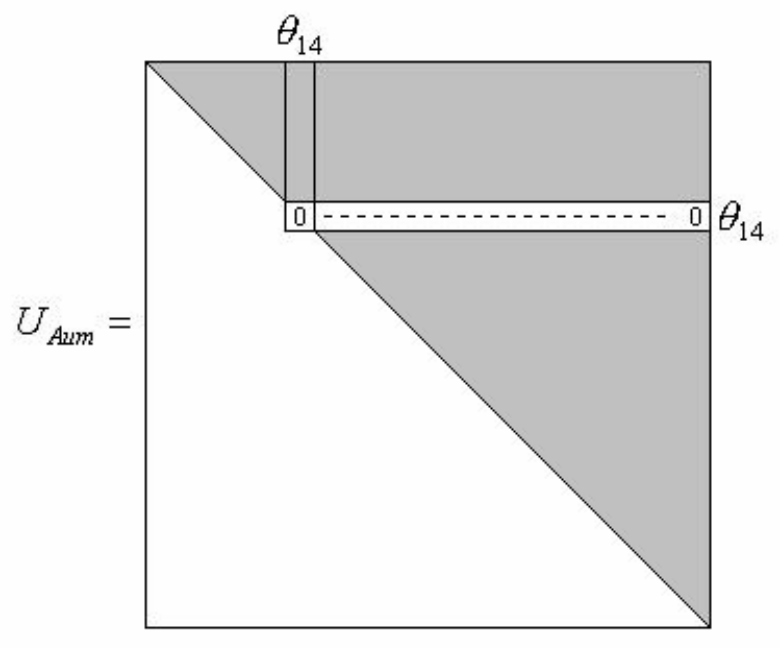

Figura 6.13: Matriz $G_{\text {Aum }}$ fatorada (teste 4)

Apareceu somente um PZ (elemento $U_{\text {Aum }}\left(\theta_{14}, \theta_{14}\right)$ ); assim, o sistema é observável como um todo, com relação ao conjunto de medidas disponível, e o caminho de fatoração associado com a submatriz $U_{\theta}$ de $U_{\text {Aum }}$ é representado através do caminho de grafo da figura 6.14.

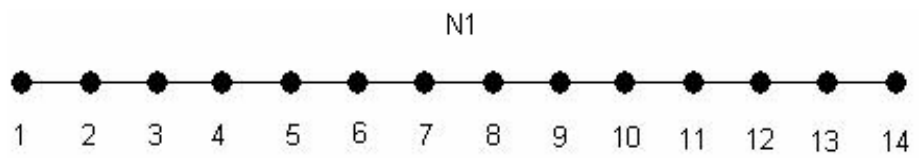

Figura 6.14: Caminho de Grafo (teste 4)

\section{Teste 5}

Considerando o conjunto de medidas indicado na figura 6.15 (medidas $P_{56}$ e $Q_{56}$ foram retiradas), e os valores dos estados aumentados, apresentados na tabela 6.2, obtem-se a matriz $G_{\text {Aum }}$ e faz-se a fatoração triangular da mesma (passos 1 e 2). 


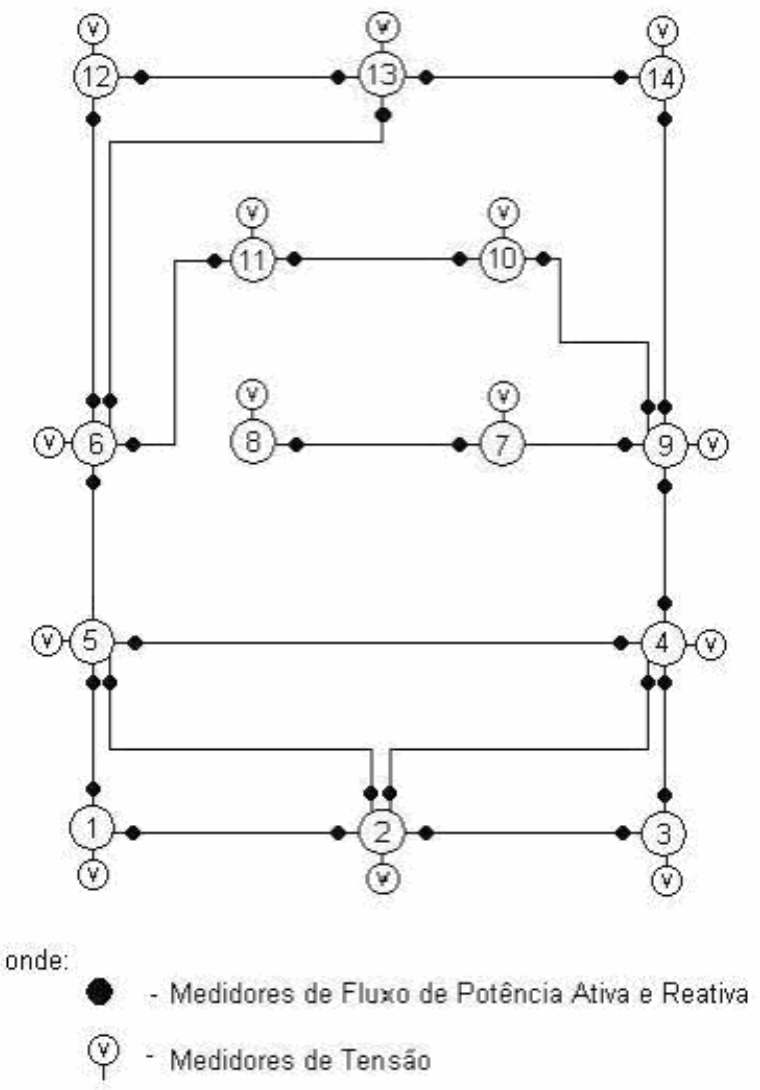

Figura 6.15: Sistema 14 barras (teste 5)

A estrutura da matriz $G_{\text {Aum }}$ fatorada é apresentada na figura 6.16.

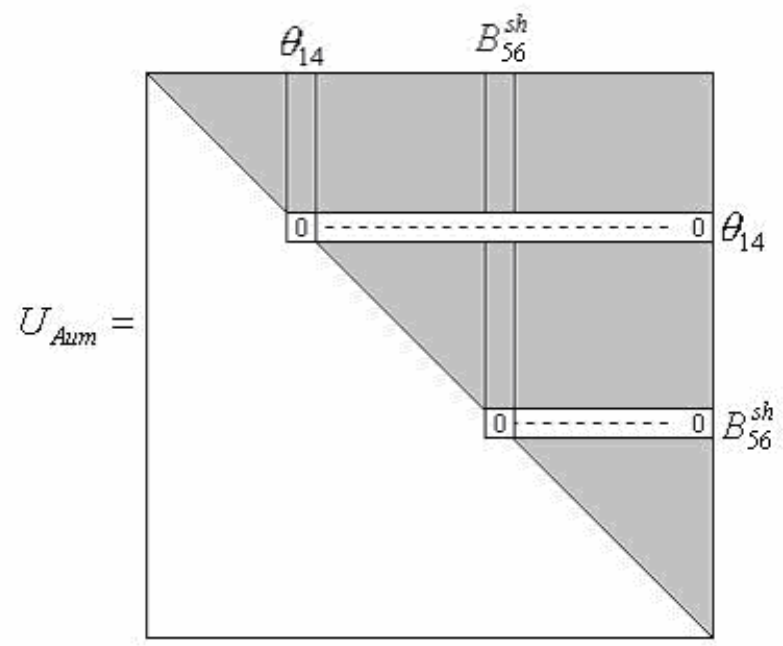

Figura 6.16: Matriz $G_{\text {Aum }}$ fatorada (teste 5) 
Como existem dois PZs $\left(U_{\text {Aum }}\left(\theta_{14}, \theta_{14}\right)\right.$ e $\left.U_{\text {Aum }}\left(B_{56}^{s h}, B_{56}^{s h}\right)\right)$, o sistema é não observável como um todo. Vá para o passo 3.

Passo 3: Parâmetro não observável: $B_{56}^{\text {sh }}$;

Passo 4: As medidas $P_{65}$ e $Q_{65}$ relacionam o parâmetro não observável;

Passo 5: $P_{65}$ e $Q_{65}$ são removidas. A nova matriz $G_{\text {Aum }}$ é obtida e fatorada.

A estrutura da nova matriz $G_{\text {Aum }}$ fatorada é:

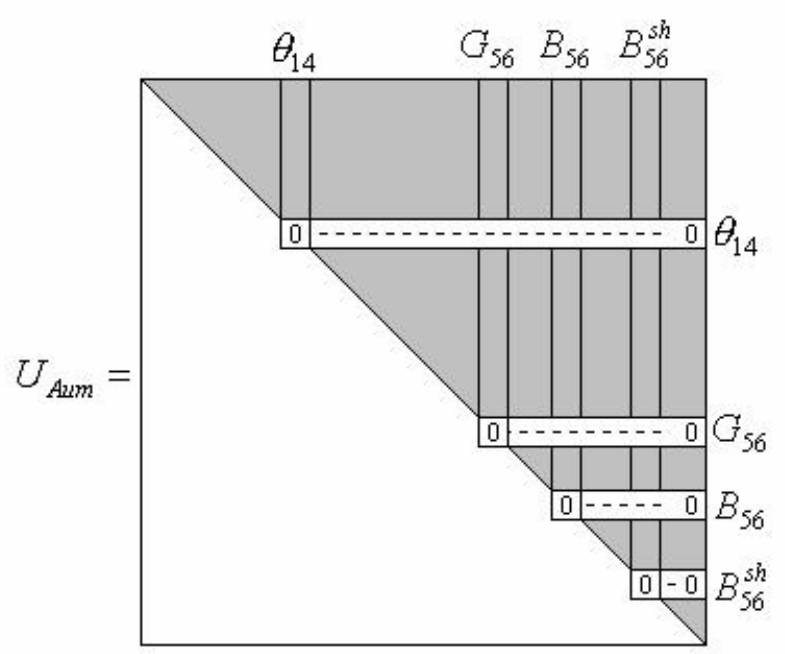

Figura 6.17: Matriz $G_{\text {Aum }}$ fatorada (teste 5)

Existem quatro PZs: $U_{\text {Aum }}\left(\theta_{14}, \theta_{14}\right), U_{\text {Aum }}\left(G_{56}, G_{56}\right), U_{\text {Aum }}\left(B_{56}, B_{56}\right)$ e $U_{\text {Aum }}\left(B_{56}^{s h}, B_{56}^{s h}\right)$; volte ao passo 3.

Passo 3: Parâmetros não observáveis: $G_{56}, B_{56}$ e $B_{56}^{\text {sh }}$;

Passo 4: Não existe medida de potência relacionando os parâmetros não observáveis; existe apenas um caminho de fatoração associado com a submatriz $U_{\theta}$ de $U_{\text {Aum }}$; o sistema é $\theta V$-observável, e o ramo que interliga as barras 5 e 6 é não observável.

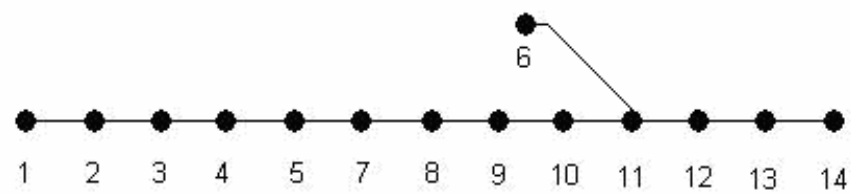

Figura 6.18: Caminho de grafo (teste 5) 


\section{Teste 6}

Considerando o conjunto de medidas indicado na figura 6.19 ( medidas $P_{87}$ e $Q_{87}$ foram retiradas), e os valores dos estados aumentados, apresentados na tabela 6.2, obtem-se a matriz $G_{\text {Aum }}$ e faz-se a fatoração triangular da mesma.

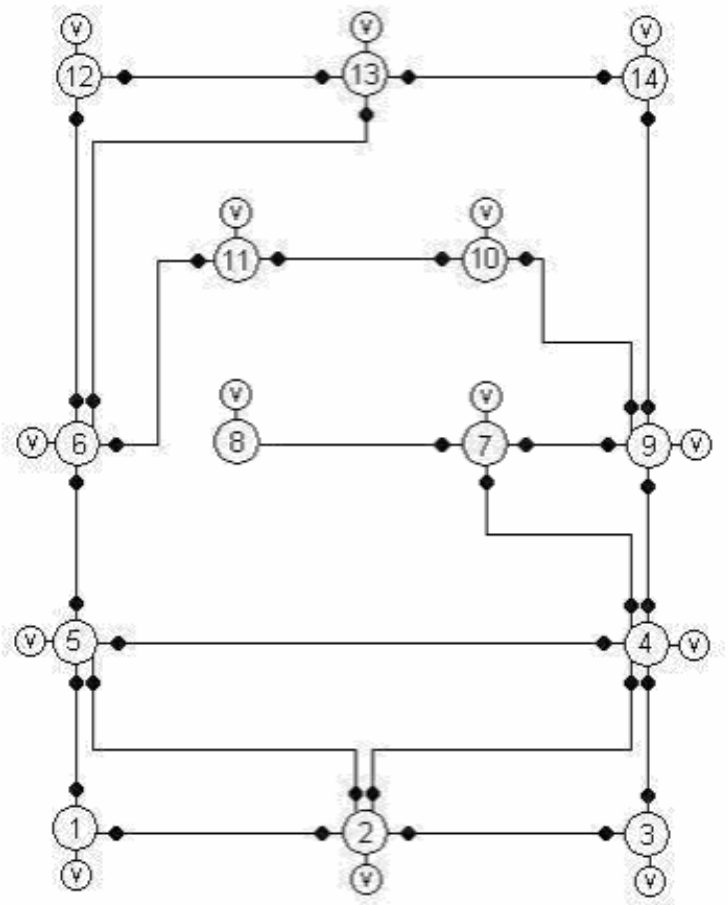

onde:

- Medidores de Fluxo de Potência Ativa e Reativa

(4) - Medidores de Tensăo

Figura 5.19: Sistema de 14 barras (teste 6) 
A estrutura da matriz $G_{\text {Aum }}$ fatorada fica:

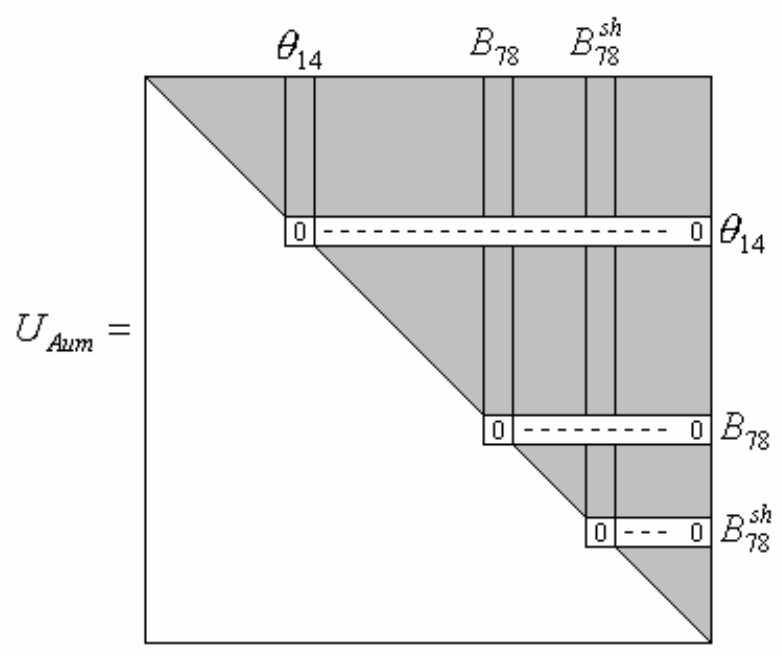

Figura 6.20: Matriz $G_{\text {Aum }}$ fatorada (teste 6)

Como existem três PZs $\left(U_{\text {Aum }}\left(\theta_{14}, \theta_{14}\right), U_{\text {Aum }}\left(B_{78}, B_{78}\right)\right.$ e $\left.U_{\text {Aum }}\left(B_{78}^{s h}, B_{78}^{s h}\right)\right)$, o sistema é não observável como um todo. Vá para o passo 3.

Passo 3: Parâmetros não observáveis: $B_{78}^{\text {sh }}$ e $B_{78}$;

Passo 4: As medidas $P_{78}$ e $Q_{78}$ relacionam os parâmetros não observáveis;

Passo 5: $P_{78}$ e $Q_{78}$ são removidas. A nova matriz $G_{\text {Aum }}$ é obtida e fatorada.

A estrutura da nova matriz $G_{\text {Aum }}$ fatorada fica:

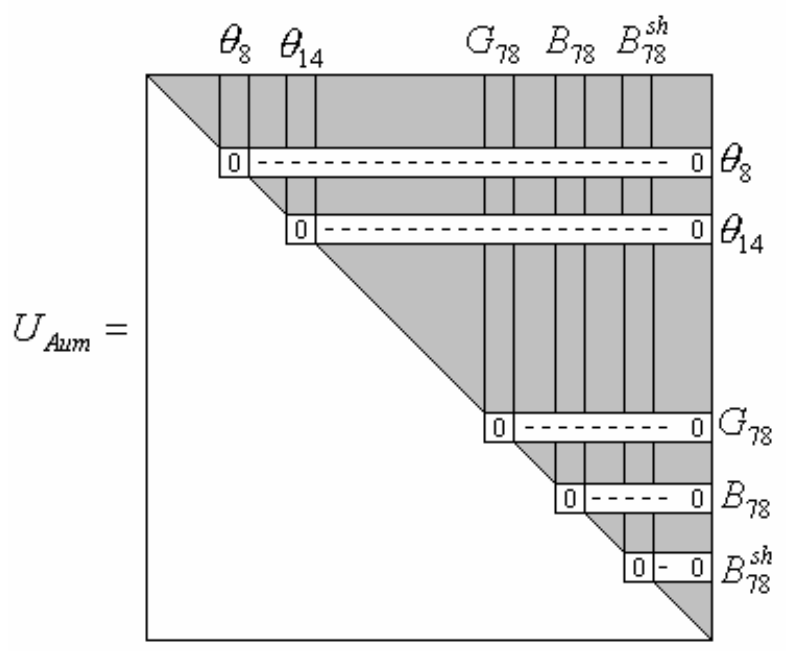

Figura 6.21 : Matriz $G_{\text {Aum }}$ fatorada (teste 6) 
Existem cinco PZs: $\quad U_{\text {Aum }}\left(\theta_{8}, \theta_{8}\right), \quad U_{\text {Aum }}\left(\theta_{14}, \theta_{14}\right), \quad U_{\text {Aum }}\left(G_{78}, G_{78}\right)$, $U_{\text {Aum }}\left(B_{78}, B_{78}\right)$ e $U_{\text {Aum }}\left(B_{78}^{\text {sh }}, B_{78}^{s h}\right)$; volte ao passo 3.

Passo 3: Parâmetros não observáveis: $G_{78}, B_{78}$ e $B_{78}^{\text {sh }}$;

Passo 4: Não existe medida de potência relacionando os parâmetros não observáveis; existem dois caminhos de fatoração associados com a submatriz $U_{\theta}$ de $U_{\text {Aum }}$; o sistema é não observável como um todo, e o ramo que interliga as barras 7 e 8 é não observável. A figura 6.22 representa os caminhos de grafo associados com a submatriz $U_{\theta}$ de $U_{\text {Aum }}$. O caminho de grafo N2 constitui uma ilha observável como um todo. Já o caminho de grafo N1 constitui uma ilha formada por apenas uma barra.
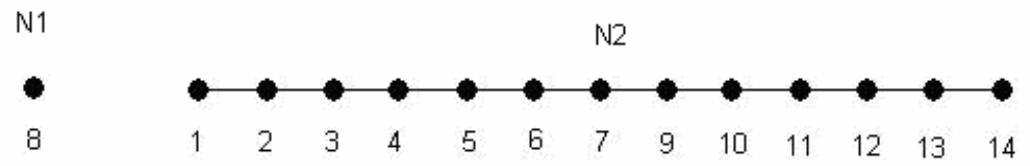

Figura 6.22: Caminhos de grafo (teste 6) 


\subsection{Testes com o sistema de $\mathbf{3 0}$ barras do IEEE}

\section{Teste 7}

O método é aplicado ao sistema de 30 barras, associado com o conjunto de medidas ilustrado na figura 6.23. Os valores dos estados aumentados, utilizados nos testes, estão na tabela 6.3.

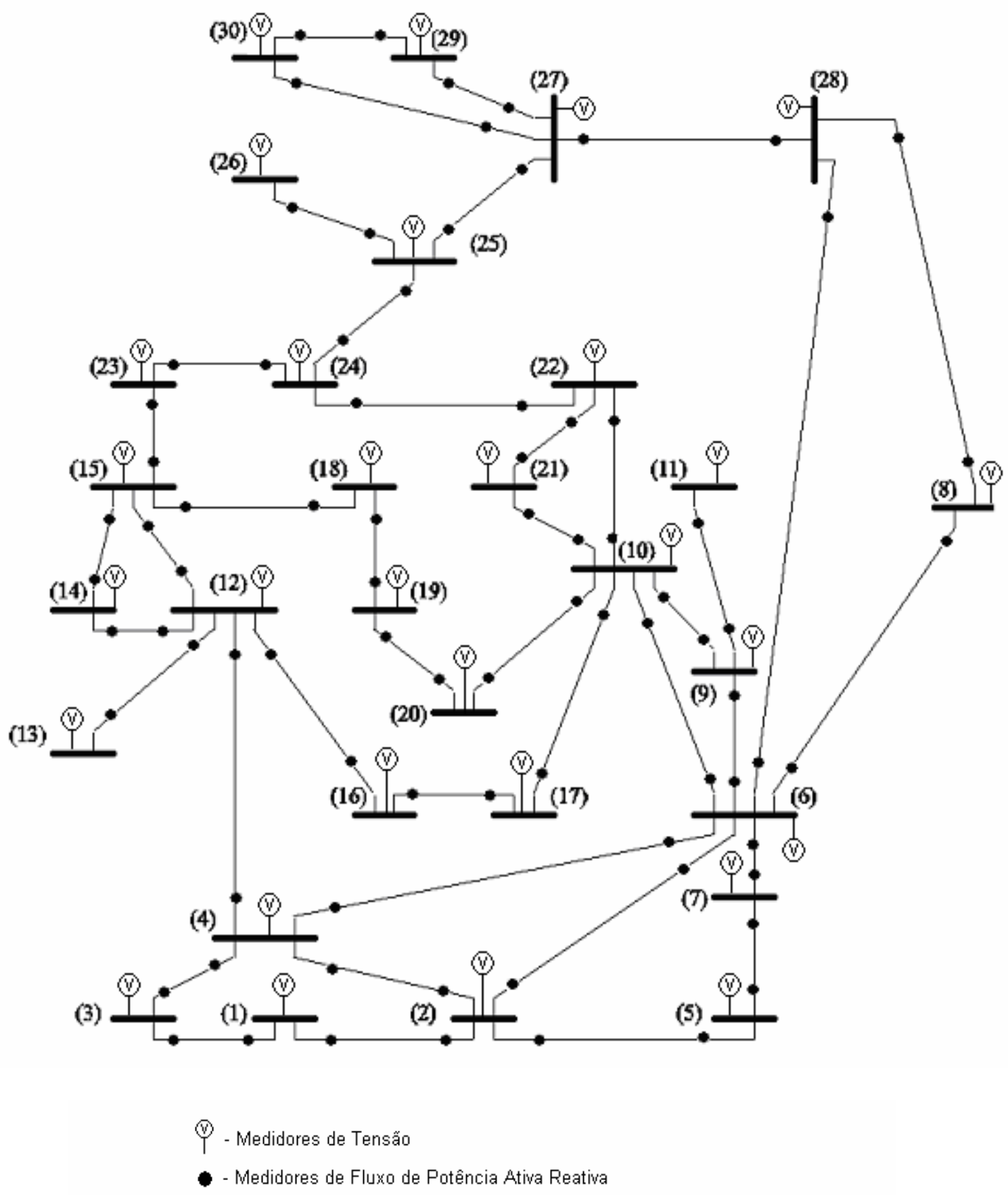

Figura 6.23: Sistema de 30 barras do IEEE 
Tabela 6.3: Estados Aumentados utilizados nos testes (30 barras)

\begin{tabular}{|c|c|c|c|c|}
\hline \multicolumn{5}{|l|}{ Dados de Linha: } \\
\hline Origem(barra) & Destino(barra) & $g(p u)$ & $\mathrm{b}(\mathrm{pu})$ & Shunt(pu) \\
\hline 1 & 2 & 0.1914 & -0.0573 & 0.0264 \\
\hline 1 & 3 & 0.7970 & -0.1805 & 0.0204 \\
\hline 2 & 4 & 0.5856 & -0.1706 & 0.0184 \\
\hline 2 & 5 & 0.8654 & -0.1934 & 0.0209 \\
\hline 2 & 6 & 0.5923 & -0.1729 & 0.0187 \\
\hline 3 & 4 & 0.1220 & -0.0403 & 0.0042 \\
\hline 4 & 6 & 0.1559 & -0.0411 & 0.0045 \\
\hline 4 & 2 & 0.5856 & -0.2560 & 0.0264 \\
\hline 5 & 7 & 0.3385 & -0.1159 & 0.0204 \\
\hline 6 & 7 & 0.2785 & -0.0825 & 0.0184 \\
\hline 6 & 8 & 0.1590 & -0.0435 & 0.0209 \\
\hline 6 & 9 & 0.1220 & -0.2080 & 0.0187 \\
\hline 6 & 10 & 0.1559 & -0.5560 & 0.0042 \\
\hline 6 & 28 & 0.2292 & -0.0590 & 0.0045 \\
\hline 8 & 28 & 0.6896 & -0.1943 & 0.0214 \\
\hline 9 & 10 & 0.1220 & -0.1100 & 0.0264 \\
\hline 9 & 11 & 0.1559 & -0.2080 & 0.0204 \\
\hline 10 & 17 & 0.2528 & -0.0845 & 0.0184 \\
\hline 10 & 20 & 0.5596 & -0.2039 & 0.0209 \\
\hline 10 & 21 & 0.1960 & -0.0755 & 0.0187 \\
\hline 10 & 22 & 0.3818 & -0.1491 & 0.0264 \\
\hline 12 & 13 & 0.5856 & -0.1400 & 0.0204 \\
\hline 12 & 14 & 0.6519 & -0.2448 & 0.0184 \\
\hline 12 & 15 & 0.3231 & -0.1301 & 0.0209 \\
\hline 12 & 16 & 0.5119 & -0.1949 & 0.0187 \\
\hline 14 & 15 & 0.4014 & -0.1974 & 0.0042 \\
\hline 15 & 18 & 0.5515 & -0.2130 & 0.0045 \\
\hline 15 & 23 & 0.5077 & -0.1981 & 0.0184 \\
\hline 16 & 17 & 0.5307 & -0.1887 & 0.0209 \\
\hline 18 & 19 & 0.3251 & -0.1284 & 0.0187 \\
\hline 19 & 20 & 0.1700 & -0.0692 & 0.0042 \\
\hline 21 & 22 & 0.0596 & -0.0281 & 0.0045 \\
\hline 22 & 24 & 0.3936 & -0.1773 & 0.0264 \\
\hline 23 & 24 & 0.6795 & -0.2564 & 0.0204 \\
\hline 24 & 25 & 0.7492 & -0.3039 & 0.0264 \\
\hline 25 & 26 & 0.7927 & -0.3424 & 0.0204 \\
\hline 25 & 27 & 0.5074 & -0.2044 & 0.0184 \\
\hline 27 & 29 & 0.8901 & -0.3881 & 0.0209 \\
\hline 27 & 30 & 0.6926 & -0.7213 & 0.0187 \\
\hline 28 & 27 & 0.5856 & -0.3960 & 0.0042 \\
\hline 29 & 30 & 0.8917 & -0.4432 & 0.0045 \\
\hline \multicolumn{5}{|c|}{ Dados de Barra: } \\
\hline \multicolumn{2}{|c|}{ Barra } & \multicolumn{2}{|l|}{ Tensão(pu) } & Ângulo (rad) \\
\hline \multicolumn{2}{|l|}{1} & \multicolumn{2}{|l|}{1.0600} & \\
\hline \multicolumn{2}{|l|}{2} & 0.7450 & \multicolumn{2}{|c|}{0.2869} \\
\hline \multicolumn{2}{|l|}{3} & 0.8100 & \multicolumn{2}{|c|}{0.2220} \\
\hline \multirow{2}{*}{\multicolumn{2}{|c|}{$\begin{array}{l}4 \\
5\end{array}$}} & 0.9190 & \multicolumn{2}{|c|}{0.1803} \\
\hline & & \multirow{2}{*}{\multicolumn{2}{|c|}{$\begin{array}{l}0.7200 \\
0.7700\end{array}$}} & \\
\hline \multicolumn{2}{|l|}{6} & & & $\frac{0.1532}{0.2382}$ \\
\hline 7 & & 0.8620 & & \\
\hline 8 & & 0.8900 & & \\
\hline 9 & & 0.9560 & & \\
\hline
\end{tabular}




\begin{tabular}{|c|c|c|}
\hline 10 & 0.7510 & 0.2635 \\
\hline 11 & 0.8570 & 0.2581 \\
\hline 12 & 0.7550 & 0.2830 \\
\hline 13 & 0.8500 & 0.2646 \\
\hline 14 & 0.9360 & 0.2010 \\
\hline 15 & 0.7450 & 0.2869 \\
\hline 16 & 0.8100 & 0.2220 \\
\hline 17 & 0.9190 & 0.1803 \\
\hline 18 & 0.7200 & 0.1532 \\
\hline 19 & 0.7700 & 0.2382 \\
\hline 20 & 0.8620 & 0.2334 \\
\hline 21 & 0.8900 & 0.2372 \\
\hline 22 & 0.9560 & 0.2808 \\
\hline 23 & 0.7510 & 0.2635 \\
\hline 24 & 0.8570 & 0.2581 \\
\hline 25 & 0.7550 & 0.2830 \\
\hline 26 & 0.8500 & 0.2646 \\
\hline 27 & 0.9360 & 0.2010 \\
\hline 28 & 0.9190 & 0.1803 \\
\hline 29 & 0.7200 & 0.1532 \\
\hline 30 & 0.7700 & 0.2382 \\
\hline
\end{tabular}

Observação 1: Devido ao tamanho do sistema de 30 barras, não serão mostrado todos os passos do processo de análise de observabilidade, como tem sido feito até o momento. Assim, a partir de agora, vamos apenas colocar os resultados dos testes realizados.

Obtêm-se a matriz $G_{\text {Aum }}$ e faz-se a fatoração triangular da mesma (passos 1 e 2). Apareceu somente um PZ (elemento $U_{\text {Aum }}\left(\theta_{30}, \theta_{30}\right)$ ); assim, o sistema é observável como um todo, com relação ao conjunto de medidas disponível, e o caminho de fatoração associado com a sub-matriz $U_{\theta}$ de $U_{\text {Aum }}$ é representado através do caminho de grafo da figura 6.24.

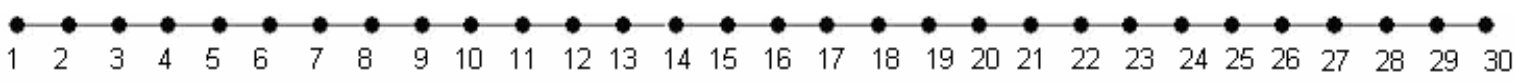

Figura 6.24: Caminho de Grafo (teste 7)

\section{Teste 8}

Considerando o conjunto de medidas indicado na figura 6.23 (medidas $P_{27,30}, Q_{27,30}, P_{30,27}, Q_{30,27}, P_{10,22}, Q_{10,22}, P_{22,10}, Q_{22,10}, P_{12,15}, Q_{12,15}, P_{15,12}$ e $Q_{1512}$ foram retiradas), e os valores dos estados aumentados, apresentados na 
tabela 6.3, obtem-se a matriz $G_{\text {Aum }}$ e faz-se a fatoração triangular da mesma (passos 1 e 2).

Como existem

dez

PZs

$\left(U_{\text {Aum }}\left(\theta_{30}, \theta_{30}\right), U_{\text {Aum }}\left(G_{27,30}, G_{27,30}\right), U_{\text {Aum }}\left(B_{27,30}, B_{27,30}\right)\right.$,

$U_{\text {Aum }}\left(B_{27,30}^{s h}, B_{27,30}^{s h}\right), U_{\text {Aum }}\left(G_{10,22}, G_{10,22}\right), U_{\text {Aum }}\left(B_{10,22}, B_{10,22}\right), U_{\text {Aum }}\left(B_{10,22}^{s h}, B_{10,22}^{s h}\right)$,

$\left.U_{\text {Aum }}\left(G_{12,15}, G_{12,15}\right), U_{\text {Aum }}\left(B_{12,15}, B_{12,15}\right), \quad U_{\text {Aum }}\left(B_{12,15}^{\text {sh }}, B_{12,15}^{\text {sh }}\right)\right)$, o sistema é não observável como um todo. Vá para o passo 3.

Passo 3: Parâmetros não observáveis: $G_{27,30}, \quad B_{27,30}, B_{27,30}^{\text {sh }}, G_{10,22}$, $B_{10,22}, B_{10,22}^{s h}, G_{12,15}, B_{12,15}$ e $B_{12,15}^{s h}$,

Passo 4: Não existe medida de potência relacionando os parâmetros não observáveis; existe apenas um caminho de fatoração associado com a submatriz $U_{\theta}$ de $U_{\text {Aum }}$; o sistema é $\theta V$-observável, e os ramos que interligam as barras 27 e 30, 10 e 22, e 12 e 15, são não observáveis. O caminho de fatoração associado com a sub-matriz $U_{\theta}$ de $U_{\text {Aum }}$ é representado através do caminho de grafo da figura 6.25.

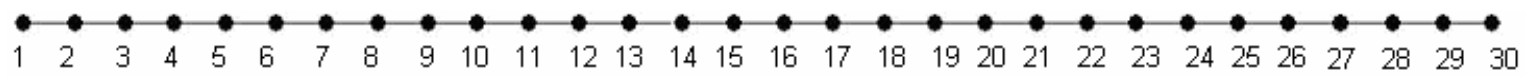

Figura 6.25: Caminho de grafo (teste 8)

\section{Teste 9}

Considerando o conjunto de medidas indicado na figura 6.23 ( medidas $P_{12,13}, Q_{12,13}, P_{13,12}, Q_{13,12}, P_{25,26}, Q_{25,26}, P_{26,25}$ e $Q_{26,25}$ foram retiradas), e os valores dos estados aumentados, apresentados na tabela 6.3, obtem-se a matriz $G_{\text {Aum }}$ e faz-se a fatoração triangular da mesma (passos 1 e 2).

Como existem sete PZs $\left(U_{\text {Aum }}\left(\theta_{14}, \theta_{14}\right), \quad U_{\text {Aum }}\left(G_{12,13}, G_{12,13}\right)\right.$, $U_{\text {Aum }}\left(B_{12,13}, B_{12,13}\right), \quad U_{\text {Aum }}\left(B_{12,13}^{\text {sh }}, B_{12,13}^{\text {sh }}\right), \quad U_{\text {Aum }}\left(G_{25,26}, G_{25,26}\right), \quad U_{\text {Aum }}\left(B_{25,26}, B_{25,26}\right) \quad$ e $\left.U_{\text {Aum }}\left(B_{25,26}^{s h}, B_{25,26}^{s h}\right)\right)$, o sistema é não observável como. Vá para o passo 3.

Passo 3: Parâmetros não observáveis: $G_{12,13}, B_{12,13}, B_{12,13}^{s h}, G_{25,26}, B_{25,26}$ e $B_{25,26}^{s h}$; 
Passo 4: Não existe medida de potência relacionando os parâmetros não observáveis; existem três caminhos de fatoração associados com a sub-matriz $U_{\theta}$ de $U_{\text {Aum }}$; o sistema é não observável como um todo, e os ramos que interligam as barras 12 e 13, e as barras 25 e 26, são não observáveis. A figura 6.26 representa os caminhos de grafo associados com a sub-matriz $U_{\theta}$ de $U_{\text {Aum }}$. O caminho de grafo N3 constitui uma ilha observável como um todo. Já os caminhos de grafo N1 e N2 constituem ilhas formadas por apenas uma barra.

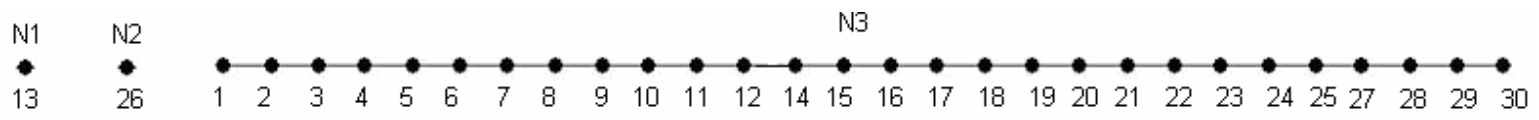

Figura 6.26: Caminhos de grafo (teste 9)

\subsection{Análise dos resultados}

Como pode ser visto, através dos testes realizados, verifica-se a eficiência do método proposto, tendo em vista a resposta coerente a que todos chegaram. Importa destacar que os testes cobriram todas as possibilidades de observabilidade, para o modelo aumentado. 


\section{Capítulo 7}

\section{Conclusões}

Analisando a literatura especializada, verifica-se que, dentre os métodos desenvolvidos para estimação de parâmetros, destaca-se o estimador de estados e parâmetros, baseado nas equações normais, que aumenta o vetor de estados para incluir os parâmetros a serem estimados. Entretanto, tal estimador pode apresentar problemas de observabilidade. Isto porque raramente o número de medidas disponível é suficiente para estimar todos os estados "aumentados", uma vez que o vetor de estados aumenta, para considerar os parâmetros, mas o conjunto de medidas continua o mesmo.

Face ao exposto, o que se propôs neste trabalho foi o desenvolvimento de um método para análise de observabilidade, para o estimador de estados e parâmetros baseado nas equações normais. Para isto, utilizou-se como base o método proposto por Bretas (1996), que se destina à análise de observabilidade para o estimador de estados convencional. Decidiu-se utilizar tal método como base, em razão de o mesmo ser simples, de fácil implementação, rápida execução e de não exigir a solução de equações algébricas.

O método proposto foi então desenvolvido, implementado e testado nos sistemas de 6, 14 e 30 barras do IEEE. Os resultados dos testes mostraram a sua eficiência. 


\section{Bibliografia}

ALÇAC, O.; VEMPATI, N.; STOTT, B.; MONTICELLI, A. (1998). Generalized state estimation. IEEE Transactions on Power Systems. Vol. 13, No. 3, Agosto.

ALLAN, M.; LAUGHTON, M. A. (1974). A general algorithm for estimating power system variables and network parameters. IEEE PES Summer Meeting \& Energy Resources Conf., Anaheim, Cal., Julho.

BRETAS, N. G. (1996). Network observability: Theory and algorithms based on triangular factorization and path graph concepts. IEE Proceedings, Generation, Transmission and Distribution, VOL.143, N¹, p. 123-128, Janeiro.

CHEN, R. L. (1990). A fast integer algorithm for observability analysis using network topology. IEEE Transactions on Power Systems, VOL.5, N³,p.1001-1009, Agosto.

CONTAXIS, G. C.; KORRES, G. N. (1988). A reduced model for power system observability analysis and restoration. IEEE Transactions on Power Systems, VOL.3, ${ }^{\circ} 4$, p.1411-1417, Novembro.

COUTO FILHO, M. B; LeIte da SILVA, A. M.; FALCÃO, D. M. (1990). Bibliography on Power System State Estimation (1968-1989). IEEE 
Transactions on Power Apparatus and Systems. VOL.5, N3, p. 950-961, Agosto.

DEBS, A.S. (1974). Parameter estimation for power systems in the steady state. IEEE Transactions on Automatic Control. Vol. Ac-19, no. 6, Dezembro.

FETZER, E. E.; ANSERSON, P. M. (1975). Observability in the State Estimation of Power Systems. IEEE Transactions on Power Apparatus and Systems. VOL.PAS-94, Nº, p. 1981-1988, Novembro/Dezembro.

FLETCHER, D.L.; STADLIN, W.O. (1983). Transformer tap position estimation. IEEE Transactions on Power Apparatus and Systems. VOL. PAS-102, No. 11, Novembro.

KRUMPHOLZ, G. R.; CLEMENTS, K. A.; DAVIS, P. W. (1980). Power Systems Observability: A Practical Algorithm Using Network Topology. IEEE Transactions on Power Apparatus and Systems. VOL.PAS-99, N4, p. 1534-1542, Julho/Agosto.

LIU, W.H.E.; WU F.F.; LUN, S.M. (1992). Estimation of parameter errors from measurement residuals in state estimation. IEEE Transactions on Power Systems. Vol. 7, No. 1, Fevereiro.

MONTICELLI, A. (1983). Fluxo de carga em redes de energia elétrica. Edgard Blücher, São Paulo.

MONTICELLI, A. (2000). Testing equality constraint hypotheses in weighted least squares state estimators. IEEE Transactions on Power Systems, VOL.15, N³, p. 950-954, Agosto.

MONTICELLI, A.; GARCIA, A. V.; SLUTSKER, I. W. (1992). Handling discardable measurements in power system state estimation. IEEE Transactions on Power Systems,VOL.7, N³, p. 1333-1340, Agosto. 
MONTICELLI, A.; WU, F. F. (1985a). Network Observability: Identification of Observable Islands and Measurement Placement. IEEE Transactions on Power Apparatus and Systems. VOL.PAS-104, N5, p. 1035-1041, Maio.

MONTICELLI, A.; WU, F. F. (1985b). Network Observability: Theory. IEEE Transactions on Power Apparatus and Systems. VOL.PAS-104, N5, p. 1042-1048, Maio.

MORI, H.; TSUZUKI, S. (1991). A fast method for topological observability analysis using a minimum spanning tree technique. IEEE Transactions on Power Systems, VOL.6, N², p.491-500, Maio.

NUCERA, R. R.; GILLES, M. L. (1991). Observability Analysis: A new topological algorithm. IEEE Transactions on Power Systems, VOL.6, N², p.466-475, Maio.

QUINTANA, V. H.; SIMOES-COSTA, A.; MANDEL, A. (1982). Power System Topological Observability Using a Direct Graph-Theoretic Approach. IEEE Transactions on Power Apparatus and Systems. VOL.PAS-101, N³, p. 617-626, Março.

SCHWEPPE, F. C. (1970). Power System Static-State Estimation, Part III: Exact Model. IEEE Transactions on Power Apparatus and Systems, VOL.PAS-89, N¹,p.130-135, Janeiro.

SCHWEPPE, F. C.; ROM, D. B. (1970). Power System Static-State Estimation, Part II: Approximate Model. IEEE Transactions on Power Apparatus and Systems, VOL.PAS-89, N¹,p.125-130, Janeiro.

SCHWEPPE, F. C.; WILDES, J. (1970). Power System Static-State Estimation, Part I: Exact Model. IEEE Transactions on Power Apparatus and Systems, VOL.PAS-89, N¹,p.120-125, Janeiro. 
SLUTSKER, I. W.; SCUDDER, J. L. (1987). Network Observability Analysis Through Measurement Jacobian Matrix Reduction. IEEE Transactions on Power Systems, VOL.PWRS-2,N²,p.331-338, Maio.

SLUTSKER, I.W.; CLEMENTS, K.A. (1996). Real time recursive parameter estimation in Energy Management systems. IEEE Transactions on Power Systems. Vol. 11, No. 3, Agosto.

SMITH, R.A. (1985). Transformer tap estimation at Florida Power Corporation. IEEE Transactions on Power Apparatus and Systems. Vol. PAS-104, No. 12, Dezembro.

PEREIRA, F.S.; London Jr., J.B.A.; Bretas, N.G. "Power System State and Parameter Estimation”. Anais do IEEE PES T\&D 2004 Latin America, São Paulo, Novembro de 2004.

ZARCO, P.; EXPÓSITO, A. G. (2000). Power System Parameter Estimation: A Survey. IEEE Transactions on Power Systems. VOL.15, $N^{\circ} 1$, p.216-222, Fevereiro. 